\title{
COMMUNITY FACTORS IN DIFFERENTIAL RESPONSES OF CHILD PROTECTIVE SERVICES
}

\author{
A DISSERTATION IN \\ Nursing \\ Presented to the Faculty of the University \\ of Missouri-Kansas City in partial fulfillment of \\ the requirements for the degree \\ DOCTOR OF PHILOSOPHY \\ by \\ A.A.S., Del Mar College, 1978 \\ B.S.N., Corpus Christi State University, 1981 \\ M.S.N., Corpus Christi State University, 1985
}

Kansas City, Missouri

2015 
(C) 2015

KAREN MCCALLUM

ALL RIGHTS RESERVED 


\title{
COMMUNITY FACTORS IN DIFFERENTIAL RESPONSES OF CHILD PROTECTIVE SERVICES
}

\author{
Karen McCallum, Candidate for the Doctor of Philosophy Degree \\ University of Missouri-Kansas City, 2015
}

\begin{abstract}
Child maltreatment results in over 3 million referrals annually to U. S. child protective services agencies and an estimated 695,000 children who are determined to be child maltreatment victims. There are ongoing concerns about the large volume and complexity of referrals and the appropriateness of an investigative model that has been criticized as adversarial, intrusive, and inappropriate for some referrals. In response, a Differential Response Model of child protection has emerged, with investigative and non-investigative alternative response paths that better acknowledge the complexities of child maltreatment and child protection. The purpose of this study was to add to the knowledge base by identifying the relationships and significance of county-level community variables in the investigative and non-investigative response paths of the Differential Response Model.
\end{abstract}

Secondary data analysis used retrospective child maltreatment data from the National Child Abuse and Neglect Data System. County-level data on social, 
economic, and demographic variables were obtained from the American Community Survey, an ongoing national survey conducted by the U.S. Census Bureau. The final dataset included 62,499 cases in 98 counties from Kentucky, Louisiana, Missouri, North Carolina, and Virginia. Predictor variables included data at child, county, and state levels. Multilevel modeling procedures were used to build multiple three-level models to analyze predictors for the binary outcome variable of child protective services differential response path: alternative response (noninvestigation) or non-alternative response (investigation).

The final three-level model demonstrated that county-level factors accounted for $12.30 \%$ of the variability in the response path outcome variable. Key results indicated that the county-level variables of housing vacancy, unemployment, child poverty, and households with public assistance were significant $(p<.05)$ in predicting response pathway. Child-level variables (report source, maltreatment type, child age, race, and number of children in the report), and the state variable of number of years since implementation of differential response were also significant $(p<.05)$ predictors in the response path outcome variable.

Results demonstrated that factors from multiple levels and contexts impact how child protection units in the Differential Response Model respond to maltreatment referrals. Research using advanced multilevel analytic procedures is essential for accurate modeling and clarification of variables in nested relationships. 


\section{APPROVAL PAGE}

The faculty listed below, appointed by the Dean of the School of Nursing and Health Studies, have examined a dissertation titled "Community Factors in Differential Responses of Child Protective Services", presented by Karen McCallum, candidate for the Doctor of Philosophy degree, and certify that in their opinion it is worthy of acceptance.

\section{SUPERVISORY COMMITTEE}

An-Lin Cheng, Ph.D., Committee Chair School of Nursing and Health Studies

University of Missouri-Kansas City

Maithe Enriquez, R.N., Ph.D.

School of Nursing

University of Missouri-Columbia

Melissa Jonson-Reid, Ph.D.

George Warren Brown School of Social Work

Washington University in St. Louis

Patricia Kelly, R.N., Ph.D.

School of Nursing and Health Studies

University of Missouri-Kansas City

Cristine Roberts, R.N., Ph.D.

School of Nursing and Health Studies

University of Missouri-Kansas City 


\section{CONTENTS}

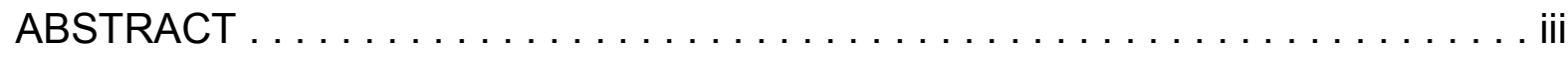

LIST OF ILLUSTRATIONS $\ldots \ldots \ldots \ldots \ldots \ldots \ldots \ldots \ldots \ldots \ldots \ldots \ldots \ldots$ vii

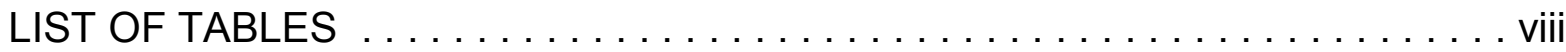

LIST OF ABBREVIATIONS $\ldots \ldots \ldots \ldots \ldots \ldots \ldots \ldots \ldots \ldots \ldots \ldots \ldots \ldots \ldots \ldots$

GLOSSARY .........................

ACKNOWLEDGMENTS $\ldots \ldots \ldots \ldots \ldots \ldots \ldots \ldots \ldots \ldots \ldots \ldots \ldots \ldots \ldots \ldots \ldots \ldots i i$

Chapter

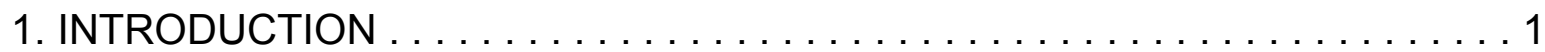

2. REVIEW OF THE LITERATURE $\ldots \ldots \ldots \ldots \ldots \ldots \ldots \ldots \ldots \ldots \ldots \ldots$

3. METHODOLOGY....................... 48

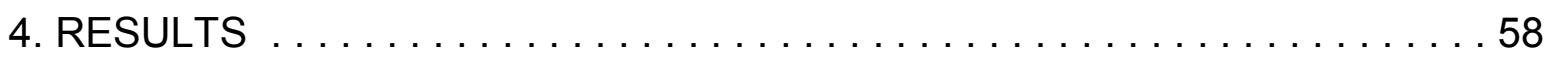

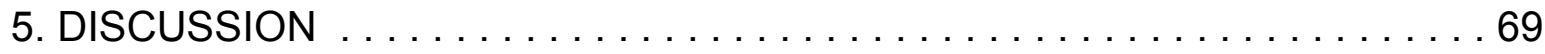

Appendix

A. UNIVERSITY OF MISSOURI-KANSAS CITY INSTITUTIONAL

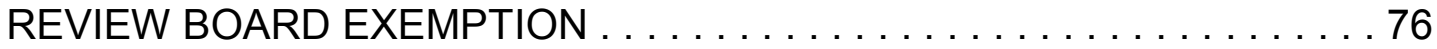

B. DATA LICENSE: NATIONAL CHILD ABUSE AND

NEGLECT DATA SYSTEM CHILD FILE $\ldots \ldots \ldots \ldots \ldots \ldots \ldots \ldots 78$

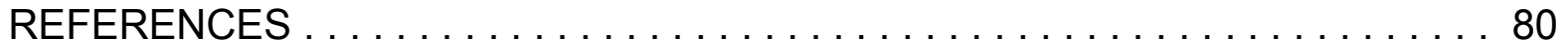

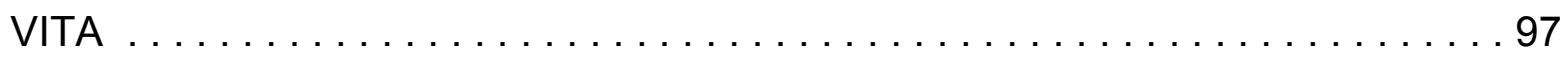




\section{LIST OF ILLUSTRATIONS}

Figure

Page

1. Model of Traditional Child Protective Services Practice $\ldots \ldots \ldots \ldots \ldots 6$

2. Differential Response Model of Child Protective Services Practice ...... .9 


\section{LIST OF TABLES}

Table

Page

1. U.S. States with CPS Differential Responses . . . . . . . . . . . . . . 10

2. Variables Considered for Possible Inclusion in the Study . . . . . . . . . 12

3. Selected Websites for Differential Response Information and Publications . . . . . . . . . . . . . . . . . . . . 19

4. Selected Publications Regarding Differential Response . . . . . . . . . 21

5. Selected Publications Regarding Child Maltreatment Risk Assessment . . . . . . . . . . . . . . . . . . . . 38

6. U.S. States with CPS Differential Responses for Inclusion in Analyses . . 51

7. Variables Included in the Study $\ldots \ldots \ldots \ldots 3$

8. Demographics and Descriptives for Study Variables . . . . . . . . . . 60

9. Variance Components . . . . . . . . . . . . . . . 63

10. Multilevel Model Analysis: Fixed Effects Statistics . . . . . . . . . . . . . 65

11. Multilevel Model Analysis: Fixed Coefficients for the Final Model . . . . . 66 


\section{LIST OF ABBREVIATIONS}

ACS - American Community Survey

ACYF - Administration on Children, Youth and Families

$A R$ - alternative response

ARS - Another Road to Safety

CAPTA - Child Abuse Prevention and Treatment Act

CBARS - Community Based Alternative Response System

CCFP - Center for Child and Family Policy

CFSR - Child and Family Services Review

CPS - Child Protective Services

CWIG - Child Welfare Information Gateway

DEM - Developmental Ecological Model

DHHS - Department of Health and Human Services

DME - Decision-Making Ecology Framework

DR - differential response

DRM - Differential Response Model

DV - dependent variable

EDV - exposure to domestic violence

FAR - Family Assessment and Response

FFCW - Fragile Families and Child Wellbeing

FFY - Federal Fiscal Year

FIPS - Federal Information Processing Standards 
GLMM - Generalized Linear Mixed Models

HFNY - Healthy Families New York

ICC - intraclass correlation

IFS - Illinois Family Study-Child Wellbeing

IPV - intimate partner violence

IRB - Institutional Review Board

IV - independent variable

LongSCAN - Longitudinal Studies of Child Abuse and Neglect

MAUP - modifiable areal unit problem

MLM - multilevel modeling

MRS - Multiple Response System

NCANDS - National Child Abuse and Neglect Data System

NDACAN - National Data Archive on Child Abuse and Neglect

NQIC - National Quality Improvement Center on Differential Response in Child Protective Services

NRC - National Research Council

NSCAW - National Survey of Child and Adolescent Well-Being

SACWIS - Statewide Automated Child Welfare Information System

UMKC - University of Missouri-Kansas City

WRM - Washington Risk Model 


\section{GLOSSARY}

alternative response - see differential response

child abuse and neglect - per federal definition of child abuse and neglect which

“...means, at a minimum, any recent act or failure to act on the part of a parent or caretaker, which results in death, serious physical or emotional harm, sexual abuse or exploitation, or an act or failure to act which presents an imminent risk of serious harm" (Child Abuse Prevention and Treatment Act (CAPTA), 1996, § 5106)

child maltreatment - used to refer collectively to forms of child abuse and neglect differential response - "a formal response of the agency that assesses the needs of the child or family without requiring a determination that maltreatment had occurred or that the child is at risk of maltreatment" (U.S. DHHS, 2003, p. 3) disposition - finding by CPS that evidence is or is not sufficient under applicable state law to determine that maltreatment occurred intake - system of receiving referrals and CPS screening of referrals of alleged maltreatment

maltreatment recurrence - a subsequent report of substantiated maltreatment in the six months following a substantiated report of maltreatment (U.S. DHHS, 2011a)

maltreatment type - the form of maltreatment alleged; may include physical, sexual, psychological, or emotional abuse or forms of neglect under applicable state law 
non-victim - determination by CPS that there is not sufficient evidence under applicable state law to conclude that child was maltreated prior child victim - a victim with prior reports of maltreatment CPS dispositions of substantiated, indicated, or alternative response victim recurrence - see maltreatment recurrence referral - notice to CPS of possible child maltreatment; may include more than one child report - referral of alleged child maltreatment received by CPS is screened in for CPS response in the form of an investigation or differential response screened in referral - referral with allegations of child maltreatment meets state criteria for further response by CPS screened out referral - referral with allegations of child maltreatment does not meet state criteria for further response by CPS Statewide Automated Child Welfare Information System (SACWIS) - automated system adopted by a state for the processing and reporting of statewide child welfare information substantiated - a CPS investigation disposition with finding that maltreatment was supported under applicable state law unsubstantiated - a CPS investigation disposition with finding that maltreatment was not supported under applicable state law victim - determination by CPS that there is sufficient evidence under applicable state law to conclude that child was maltreated 


\section{ACKNOWLEDGMENTS}

In grateful acknowledgment of the source and use of data, the author adopted the following statement:

The analyses presented in this publication were based on data from the National Child Abuse and Neglect Data System (NCANDS) Child File, Federal Fiscal Year (FFY) 2010. These data were provided by the National Data Archive on Child Abuse and Neglect at Cornell University, and have been used with permission. The data were originally collected under the auspices of the Children's Bureau with funding from the Children's Bureau. Funding was provided by the Children's Bureau, Administration on Children, Youth and Families, Administration for Children and Families, U.S. Department of Health and Human Services. The collector of the original data, the funding agency, NDACAN, Cornell University, and the agents or employees of these institutions bear no responsibility for the analyses or interpretations presented here. The information and opinions expressed reflect solely the opinion of the author. (U.S. DHHS, 2011c, p. iii)

The author also wishes to acknowledge and offer profuse thanks to her dissertation committee members, Drs. Cheng, Enriquez, Jonson-Reid, Kelly, and Roberts for the wealth of their expertise, guidance, feedback, and unending patience. Judy Jellison and Nancy Hoover deserve special thanks for assistance and endless patience in helping the author matriculate through the system of forms, guidelines, and deadlines. The author gratefully acknowledges Susan Sykes Berry and Jonice Rogers for their experienced and unrelenting assistance in providing library services. Diane Wittling is also much appreciated for her assistance in maintaining contacts throughout this work. Of course, no work of this duration and magnitude could have been completed without the continuing support of family members, especially Richard and Michael. 


\section{CHAPTER 1}

\section{INTRODUCTION}

Child maltreatment, including child abuse and neglect, is a significant problem resulting in an estimated 3.3 million referrals, involving approximately six million children, annually to child protective services (CPS) agencies in the United States (U.S. Department of Health and Human Services (DHHS), 2011a). There are substantial variations in state responses to maltreatment referrals. Local CPS agencies responded to a national average of $60.7 \%$ (range $25.2-98.7 \%$ ) of these initial referrals while declining to respond to $39.3 \%$ (range $1.3-74.8 \%$ ) of the referrals (U.S. DHHS, 2011a).

Investigations by CPS agencies in Federal Fiscal Year (FFY) 2010 determined that an estimated 695,000 children were victims of abuse or neglect (U.S. DHHS, 2011a). Neglect was the most common form of maltreatment $(78.3 \%)$, followed by physical abuse (17.6\%), sexual abuse $(9.2 \%)$, and psychological abuse $(8.1 \%)$ with some victims suffering multiple types of abuse. Those in a parental relationship with the victim perpetrated $81.2 \%$ of the abuse with biological parents perpetrating $84.2 \%$ of parental abuse. Step-parents perpetrated only $4.0 \%$ of the abuse. Women perpetrated $53.6 \%$ of the abuse compared to $45.2 \%$ committed by men. Of all perpetrators, $36.3 \%$ were 20 to 29 years of age. In $58.6 \%$ of cases 
accepted by CPS, the referral was made by a professional working with children. Medical professionals including nurses accounted for only $8.2 \%$ of these cases.

Based on national CPS data (U.S. DHHS, 2011a), there were an estimated 1,560 (2.07 deaths per 100,000) children who died from child maltreatment with $79.4 \%$ of fatalities in children less than four years of age. The fatality rate was somewhat higher for boys (2.51 per 100,000) than girls (1.73 per 100,000). Neglect, without co-occurring other maltreatment types, accounted for $32.6 \%$ of maltreatment fatalities whereas $40.8 \%$ of fatalities were caused by multiple maltreatment types. It has been shown that use of a single data source, such as CPS or death certificate data, significantly underestimates child maltreatment fatality rates (Crume, DiGuiseppi, Byers, Sirotnak, \& Garrett, 2002).

In non-fatal child maltreatment cases, $21.9 \%$ of the victims were African American, $21.4 \%$ were Hispanic, $44.8 \%$ were White, and $48.5 \%$ were female. More than one third of the victims were under four years of age with children less than one year of age having the highest rate of victimization (20.6 per 1,000). A study utilizing non-CPS data reported the occurrence of child maltreatment at a rate of 138 per 1,000 children (Finkelhor, Ormrod, Turner, \& Hamby, 2005). Comparison of the incidence rate of child maltreatment (929.65 per $100,000)$ to incidence rates for all cancers (497.65 per 100,000), or for childhood cancers (17.96 per 100,000), provides perspective and evidence of the significance and scope of the problem of child maltreatment.

Though some victims of child maltreatment may demonstrate resilience in response to abuse (Madsen \& Abell, 2010), many more victims experience a variety 
of negative health and social outcomes such as developmental dysfunction, substance abuse, criminal behavior, and an increased risk for morbidity persisting throughout adulthood (Child Welfare Information Gateway (CWIG), 2013; English et al., 2005; Gilbert et al., 2009; Hussey, Chang, \& Kotch, 2006; Jonson-Reid, Drake, \& Kohl, 2009; Smith, Ireland, Thornberry, \& Elwyn, 2008; U.S. DHHS, 2005). Shortand long-term consequences of child maltreatment may include death, traumatic brain injury, depression, suicide, post-traumatic stress disorder, high-risk sexual behaviors, poor academic or job performance, and high-risk negative health behaviors. The economic cost of child abuse and neglect in the U.S. is conservatively estimated at $\$ 103.8$ billion annually (Wang \& Holton, 2007) with an estimated lifetime cost of $\$ 124$ billion for new cases of substantiated child abuse and neglect each year (Fang, Brown, Florence, \& Mercy, 2012).

\section{Child Maltreatment Definition}

Current recognition of child maltreatment is based on the federal definition of child abuse and neglect which "...means, at a minimum, any recent act or failure to act on the part of a parent or caretaker, which results in death, serious physical or emotional harm, sexual abuse or exploitation, or an act or failure to act which presents an imminent risk of serious harm" (Child Abuse Prevention and Treatment Act (CAPTA), 1996, § 5106). Beyond this federal minimum definition, the definition of child maltreatment and the evidence required to demonstrate that maltreatment occurred vary according to state laws, agency policies, and local practices (U.S. DHHS, 2011a). 
All 50 states have laws defining maltreatment and requiring identified categories of personnel to report suspected child abuse or neglect (CWIG, 2009, 2012). Nurses and other health care providers, teachers and other school personnel, law enforcement officers, and social workers are among those required by law to report suspected maltreatment. As mandated reporters, nurses are legally required to report suspected child abuse or neglect to the state child welfare agency. Failure to report allegations may subject the nurse to civil and/or criminal penalties, including possible fines and jail time. The nurse is responsible for knowing state and local laws and institutional policies and procedures for fulfilling the mandate for reporting suspected abuse. The Child Welfare Information Gateway (http://www.childwelfare.gov), administered by the U.S. DHHS, has extensive information, links to additional resources, and online state statute and policy information (http://www.childwelfare.gov/systemwide/laws policies/state/index.cfm).

\section{Child Protective Service Models}

Historically, CPS agencies have practiced under a traditional medical-legal model of child welfare focused on identification and protection of victims and identification and prosecution of perpetrators. The procedure for responding to referrals for suspected maltreatment varies somewhat from state to state, but the process begins when CPS receives referrals from various sources including hotline calls from members of the general public, police or school officials, or from others required by law to report (mandated reporters) suspected maltreatment (U.S. DHHS, 2011a). Whether the referral intake office is centralized at the state level or administered at the county level, CPS officials screen each referral to determine if 
the circumstances reported meet that state's criteria for CPS investigation. Referrals that do not meet the criteria for investigation are screened out of the CPS system and receive no further CPS response. Examples of referrals that may be screened out include those for which there is incomplete information, a false address, or insufficient support for the claim of maltreatment. Referrals involving perpetration by a person who is not in the role of parent or caregiver are referred to law enforcement officials for investigation and possible prosecution under criminal laws. Referrals that are accepted by CPS are screened in for investigation and referred to the local CPS office. CPS responds to screened in referrals by investigating the maltreatment allegations and making a report of findings, or disposition, as to whether the alleged maltreatment occurred or whether the child is at risk of maltreatment. A report is assigned a finding, or disposition, of substantiated, indicated, or founded (U.S. DHHS, 2011a) when it is determined that the alleged maltreatment, or risk of maltreatment, met evidentiary requirements under state law. When findings do not meet the legal criteria for substantiation as maltreatment, the report may be assigned a finding of unsubstantiated or not indicated (U.S. DHHS, 2011a). As disposition categories are determined by state law and agency regulation and policy, the categories vary somewhat from state to state. This model of traditional CPS practice is depicted in Figure 1. 


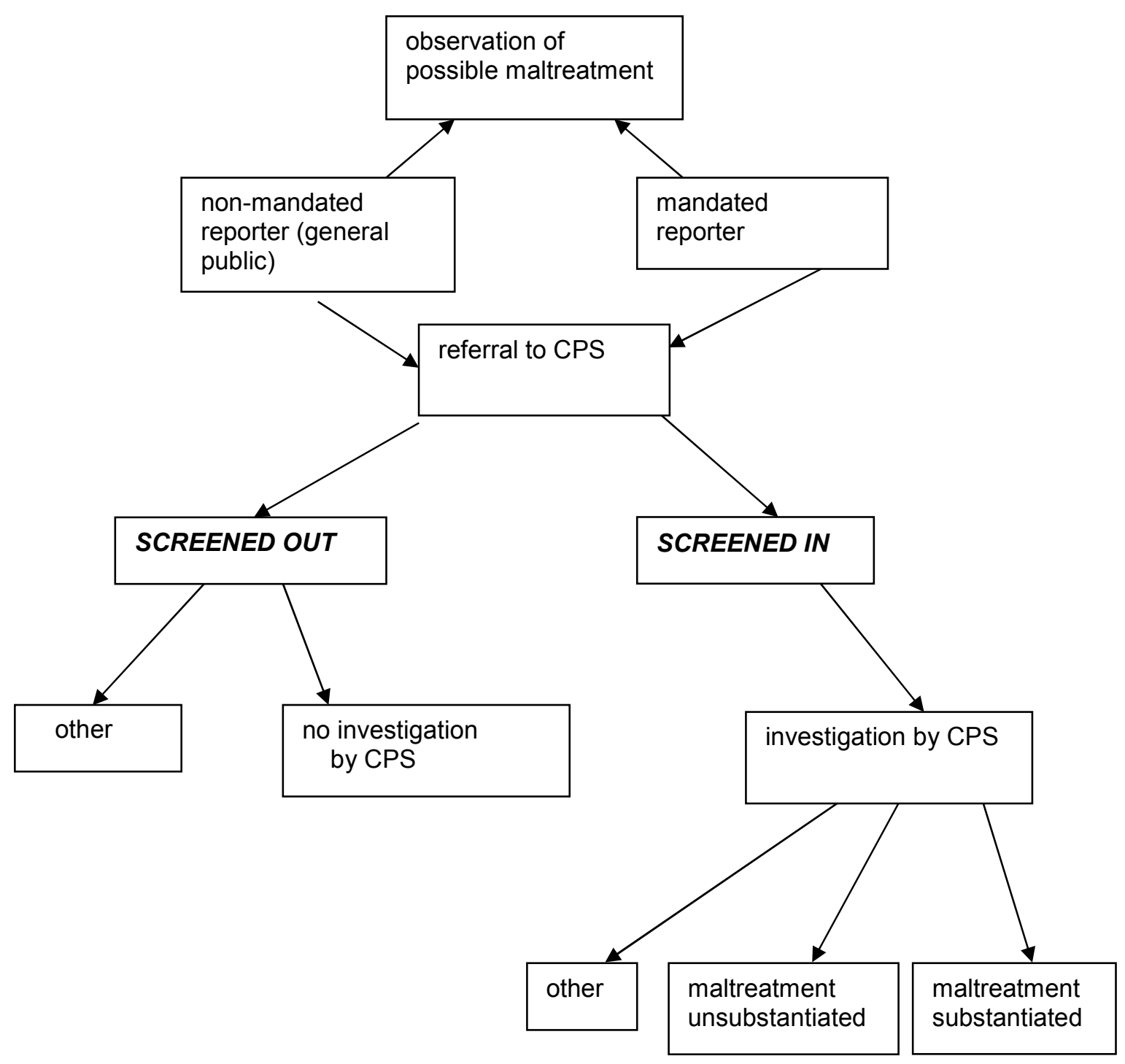

Figure 1. Model of Traditional Child Protective Services Practice. CPS = Child Protective Services.

In the traditional medical-legal model of CPS practice (Figure 1), all screened in referrals are investigated in a process that has been viewed as adversarial, intrusive, and inappropriate for some referrals (English, Wingard, Marshall, Orme, \& Orme, 2000; Schene, 2001; Waldfogel, 1998). Since the 1990s, there have been 
ongoing concerns about the volume and complexity of referrals and the capacity and appropriateness of the traditional CPS practice model (Schene, 2001; Shusterman, Hollinshead, Fluke, \& Yuan, 2005; Waldfogel, 1998). A differential response model (DRM) of CPS practice has emerged in a number of states to address these issues. Though differential response (DR) is known by various names, such as alternative response (AR), multiple response, dual path model, and other names, there is movement to focus on the DR label as it is indicative of CPS responses that treat referrals differentially based on assessment of needs in each case (CWIG, 2008; FRIENDS, 2007; Merkel-Holguin, Kaplan, \& Kwak, 2006; Schene, 2005). For the purposes of a national study of CPS practices, alternative responses (AR) based on the DRM were defined "as a formal response of the agency that assesses the needs of the child or family without requiring a determination that maltreatment had occurred or that the child is at risk of maltreatment" (U.S. DHHS, 2003, p. 3).

A generic DRM includes a non-investigative path in addition to the traditional CPS investigation path as a possible response to screened in referrals. Initial screening of referrals identifies levels of child maltreatment risk and directs high-risk referrals to the investigation pathway and low to moderate risk referrals to an alternative or non-investigative pathway. The non-investigative path includes some form of family assessment in which safety, risk, and family strengths, needs, and resources are assessed. Responses by CPS to these assessments may include findings that no services are needed, voluntary services are recommended, or services are needed. The family may decline or agree to voluntary services. If the 
family refuses needed services, the case may be changed to the investigative path (Kaplan \& Merkel-Holguin, 2008).

Essential to the DRM is that there is no substantiation of maltreatment and no identification of a perpetrator in the non-investigative (AR) pathway. In the AR path, CPS findings are assigned to disposition categories such as alternative response, non-victim; alternative response, victim; or maltreatment indicated or not indicated (U.S. DHHS, 2011a). A generic DRM of CPS practice is depicted in Figure 2. 


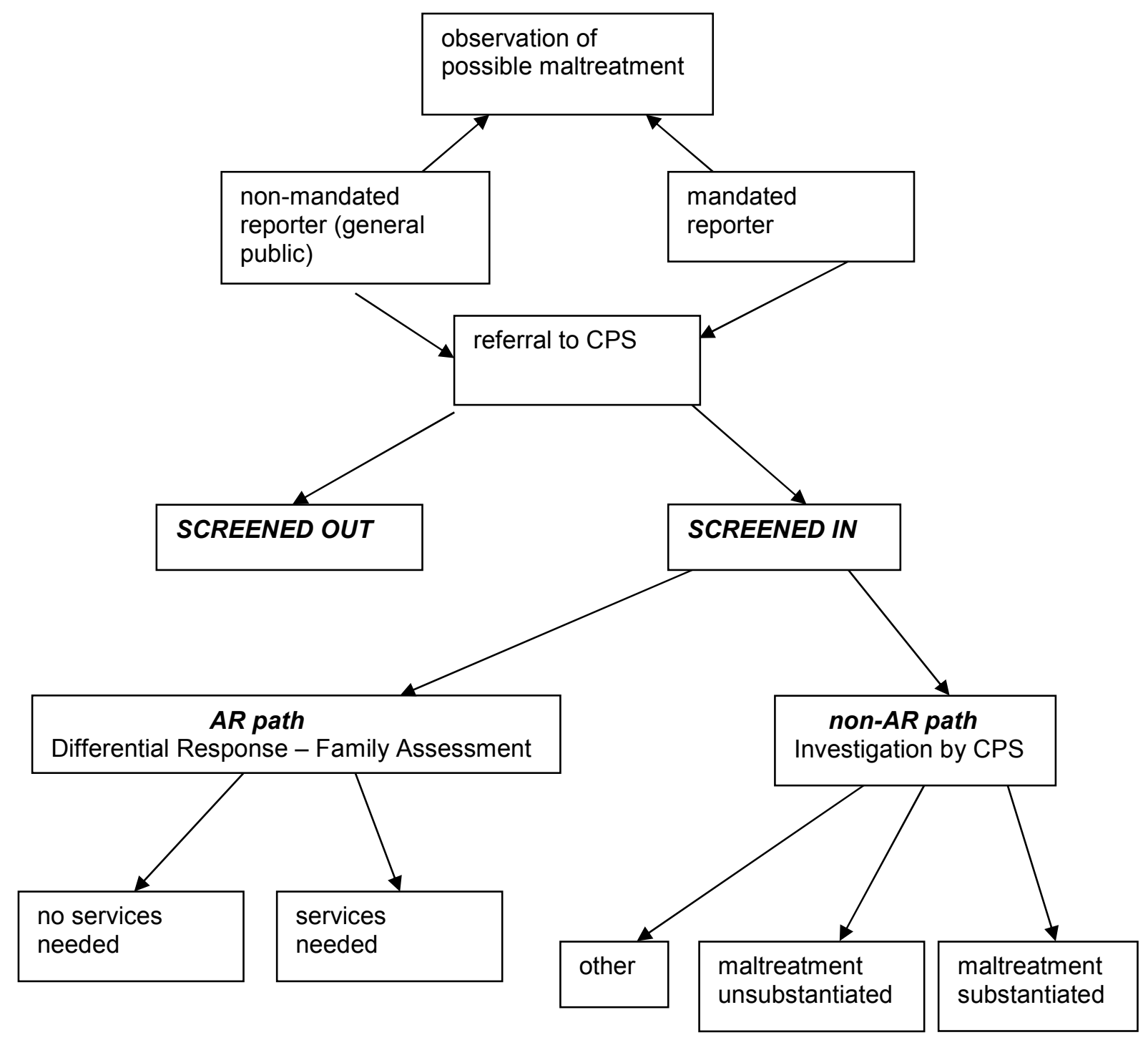

Figure 2. Differential Response Model of Child Protective Services Practice. CPS = Child Protective Services; AR = alternative response.

There are 24 states reportedly having some form of differential CPS practice (Casey Family Programs, 2011b; National Quality Improvement Center on Differential Response in Child Protective Services (NQIC), 2009), with 12 states having implemented DR on a statewide basis. Only 14 states, as identified in Table 
1, reported CPS DR dispositions in their reports to the National Child Abuse and

Neglect Data System (NCANDS) for FFY 2010 (U.S. DHHS, 2011a).

Table 1

U.S. States with CPS Differential Responses

\begin{tabular}{|c|c|c|c|c|c|c|c|}
\hline State & $\begin{array}{l}\text { 1st Year } \\
\text { DR }\end{array}$ & $\begin{array}{l}\text { Year } \\
\text { State- } \\
\text { Wide } \\
\end{array}$ & $\begin{array}{l}\text { FFY } \\
2010 \text { DR } \\
\text { Data to } \\
\text { NCANDS }\end{array}$ & $\begin{array}{l}\text { Enabled } \\
\text { by State } \\
\text { Statute }\end{array}$ & $\begin{array}{c}\text { No. of } \\
\text { Paths for } \\
\text { Screened } \\
\text { In Reports } \\
\end{array}$ & $\begin{array}{l}\text { Path for } \\
\text { Screened } \\
\text { Out } \\
\text { Reports } \\
\end{array}$ & $\begin{array}{l}\text { Risk / } \\
\text { SDM } \\
\text { tool to } \\
\text { Assign } \\
\text { Path } \\
\end{array}$ \\
\hline California & 2004 & No & No & Yes & 2 & Yes & $U$ \\
\hline Colorado & $\begin{array}{l}2010 \text { start } 3 \\
\text { year pilot }\end{array}$ & $\begin{array}{l}5 \\
\text { counties }\end{array}$ & No & Yes & 2 & $U$ & Yes \\
\hline Connecticut & in planning & $\mathrm{U}$ & No & Yes & U & $U$ & $U$ \\
\hline Hawaii & 2005 & Yes & No & Yes & 2 & Yes & Yes \\
\hline Illinois & 2010 & No & No & Yes & 2 & No & $U$ \\
\hline Indiana & $2005-2009$ & Yes & No & No & $U$ & Yes & Yes \\
\hline Kentucky & 2001 & Yes & Yes & Yes & 4 & No & Yes \\
\hline Louisiana & 1999 & & Yes & Yes & 2 & & \\
\hline Maine & 2001 & Yes & No & No & 2 & No & Yes \\
\hline Minnesota & 1997 & 2005 & Yes & Yes & 2 & No & Yes \\
\hline Missouri & 1994 & Yes & Yes & Yes & 2 & Yes & Yes \\
\hline Nevada & $\begin{array}{l}20073 \text { pilot } \\
\text { counties }\end{array}$ & $\begin{array}{l}2008- \\
2009^{a}\end{array}$ & Yes & Yes & 2 & $U$ & $U$ \\
\hline New Jersey & 2007 & No & No & Yes & 1 & $U$ & $U$ \\
\hline New York & 2008 & No & Yes & Yes & 2 & No & No \\
\hline $\begin{array}{l}\text { North } \\
\text { Carolina }\end{array}$ & 2001 & Yes & Yes & Yes & 2 & No & Yes \\
\hline Ohio & 2006 & $\begin{array}{l}\text { In } 25 / 88 \\
\text { counties }\end{array}$ & No & Yes & 2 & No & No \\
\hline Oklahoma & 1997 & Yes & Yes & Yes & 2 & No & No \\
\hline Pennsylvania & $\mathrm{U}$ & Yes & No & $U$ & 1 & $N / A$ & $U$ \\
\hline Tennessee & 2005 & No & Yes & Yes & 3 & Yes & Yes \\
\hline Vermont & July 2009 & 2010 & Yes & Yes & 2 & & \\
\hline Virginia & 2002 & Yes & Yes & No & 2 & No & Yes \\
\hline Washington & 1994 & & Yes & Yes & 2 & & \\
\hline Wisconsin & $\begin{array}{l}\text { FFY } 2010 \\
\text { pilot }\end{array}$ & $\begin{array}{l}5 \\
\text { counties }\end{array}$ & Yes & $\begin{array}{l}\text { Yes for } \\
\text { pilot }\end{array}$ & & & \\
\hline Wyoming & $2005^{b}$ & Yes & Yes & Yes & 2 & Yes & Yes \\
\hline
\end{tabular}


In contrast to the traditional investigation path, the non-investigation (AR) path focuses on assessing family needs with engagement and encouragement rather than use of an adversarial and threatening approach. The goal is to identify needed services and support rather than to identify a victim and punish a perpetrator (Conley, 2007). In both the traditional and DR models, CPS practice is directed toward successfully meeting child safety, well-being, and permanency (CWIG, 2008; Kaplan \& Merkel-Holguin, 2008). Research on the relative effectiveness of this approach is just emerging (Drake, 2013).

\section{Research Questions}

The health and well-being of children and their families are linked to the health and well-being of the communities in which they live (Belsky, 1980, 1993; Bronfenbrenner, 1977; National Research Council (NRC), 1993. The DRM focuses responses to referrals differentially based on assessment of needs in each case; and encourages collaboration of families and community services. Thus, one might expect DRM path assignment to be impacted by child and family characteristics to a much greater extent than by community factors. Understanding the relationship of county-level community factors to DRM path assignment is important because of the significant consequences and costs of child maltreatment, the importance of community collaboration in the DRM, and the county-level organization of CPS in many states. Based on review of the literature and consistent with the developmental ecological framework, consideration was given to the possible contributions of factors in multiple domains including characteristics of the child, 
circumstances of the report, and county- and state-level characteristics. Specific variables initially considered for possible inclusion in the study are presented in Table 2.

Table 2

Variables Considered for Possible Inclusion in the Study

\begin{tabular}{|c|c|c|}
\hline Individual Level & Community Level & CPS Response Paths \\
\hline $\begin{array}{l}\text { Child Characteristics } \\
\text { Child ID } \\
\text { Age } \\
\text { Sex } \\
\text { Race } \\
\text { Ethnicity } \\
\text { Living arrangement } \\
\text { Disability or impairment } \\
\text { Alcohol abuse } \\
\text { Substance abuse } \\
\text { Prior victim }\end{array}$ & $\begin{array}{l}\text { County-Level Characteristics } \\
\text { Urban or rural } \\
\text { Persons under age } 5 \text { years } \\
\text { Persons under age } 18 \text { years } \\
\text { Persons foreign born } \\
\text { Race } \\
\text { Single parent household } \\
\text { Median household income } \\
\text { Persons }<18 \text { years below } \\
\text { poverty level } \\
\text { High school graduates age } 25+\end{array}$ & $\begin{array}{l}\text { AR investigation } \\
\text { AR non-investigation }\end{array}$ \\
\hline $\begin{array}{l}\text { Caretaker Characteristics } \\
\text { Disability or impairment } \\
\text { Alcohol abuse } \\
\text { Substance abuse } \\
\text { Domestic violence } \\
\text { Inadequate housing } \\
\text { Financial problem } \\
\text { Public assistance }\end{array}$ & $\begin{array}{l}\text { State-Level Characteristics } \\
\text { Year DR first implemented } \\
\text { Intake level: centralized or local }\end{array}$ & \\
\hline $\begin{array}{l}\text { Perpetrator Characteristics } \\
\text { Perpetrator ID } \\
\text { Age at report } \\
\text { Sex } \\
\text { Race } \\
\text { Ethnicity } \\
\text { Military member } \\
\text { Relationship to child }\end{array}$ & & \\
\hline $\begin{array}{l}\text { Report Characteristics } \\
\text { Report ID } \\
\text { Report date } \\
\text { Report source } \\
\text { Maltreatment type }\end{array}$ & & \\
\hline
\end{tabular}

Note. ID = identification; DR = Differential Response; AR = Alternative Response. 
The purpose of this study was to fill a gap in the knowledge base by identifying the significance of county-level community factors to AR and non-AR paths in the DRM. The specific aims of the research study were to:

1. Identify and describe the relationships of county-level community factors to CPS response paths in differential response systems.

2. Explore and describe the relationships of county-level community factors to CPS response paths in differential response systems while controlling for child, family, and case characteristics.

The research questions addressed in the study were:

1. What are the differences in child, family, and case characteristics between cases assigned to CPS investigation path (non-AR) compared to the AR path?

2. What is the relationship of county-level community factors to AR and non-AR path assignment when controlling for child, family, and case characteristics?

To address the specific aims and research questions, analytic strategies for this study included descriptive, multivariate, and multilevel modeling statistical techniques.

\section{Theoretical Framework}

Theoretical frameworks provide systematic organization of concepts to assist in the identification of study variables and their possible relationships. The framework also provides guidance in analytic strategies and interpretation and application of study findings. Early child maltreatment research was based on models that focused on pathology within the individual perpetrator (NRC, 1993).

Research efforts have frequently been organized based on the type of maltreatment 
and often focused on singular or limited factors to examine child maltreatment and child protection.

As research evidence and knowledge accumulated, theory development evolved in recognition that child maltreatment is complex, multi-dimensional, and affected by multiple interactive processes in multiple domains. In a 1993 report on child abuse and neglect research, the NRC recommended that child maltreatment be viewed from an ecological and developmental perspective with a focus on facilitating healthy child development. This developmental ecological model (DEM) allows for conceptualizations of complex, multifactorial, multilevel interactions and processes and allows for multidisciplinary efforts in maltreatment research, identification, prevention, and intervention.

Within the DEM, there are four nested domains including intrapersonal (individual or ontogenic), interpersonal (microsystem), community (exosystem), and society (macrosystem) (Belsky, 1980, 1993; Bronfenbrenner, 1977). The intrapersonal domain includes individual characteristics, and the interpersonal domain includes family characteristics as well as parent-child interactions. Neighborhoods, schools, work places, and geopolitical areas are examples of contexts in the community domain. The society domain includes contexts such as governmental and institutional laws and policies, and professional and cultural considerations. There are multiple biopsychosociocultural, political, and economic contexts and interactive processes located within and across these domains. This model is interactive in that the domains, contexts, and factors may influence and be influenced by other domains, contexts, and factors (Belsky, 1980, 1993; 
Bronfenbrenner, 1977; Hamilton, 1989; Little \& Kantor, 2002). Within these contexts, there are multiple factors which may be predictive, protective, or suggestive of increased risk of child maltreatment. Maltreatment is more likely to occur when protective factors are absent, decreased, or overwhelmed by the presence of risk factors (Belsky, 1993; Bronfenbrenner, 1977; Hamilton, 1989; Little \& Kantor, 2002).

Other frameworks have been used in the study of child maltreatment issues and in providing evidence for the basis of child protection responses. For example, Herring (2009) applied evolutionary theory and behavioral biology concepts and research to address the relationship of male parental investment based on the premise that lower parental involvement represents higher risk of child maltreatment perpetration by the male parental figure. Attribution theory with a social-cognitive approach has been used to study physical child abuse in terms of the inference of responsibility for the perceived aggression of another and the level of maternal stress in a sample of low income African American mothers (Graham, Weiner, Cobb, \& Henderson, 2001). There was greater risk for harsh punishment and abusive behavior in mothers with higher stress who perceived the child as responsible for intentional misbehavior.

The Decision-Making Ecology Framework (DME) (Baumann, Dalgleish, Fluke, \& Kern, 2011) represents an alternative theory for use in the study of CPS system factors related to child maltreatment and DR practice. The DME, which can be viewed as theory nested within an ecological framework, places CPS decisionmaking within a systems perspective. Case, external, organizational, and decision- 
maker factors in the DME combine to influence decision-making and outcomes of decisions. CPS decisions to screen in referrals, or to assign referrals to a noninvestigation path, or to substantiate a report of maltreatment are important because such determinations may have implications not only for the life and safety of the child, but also for delivery of services and prosecution of perpetrators. The DME provides a robust and interactive framework for identifying variables and describing variable relationships that may influence CPS decision-making processes. For example DePanfilis and Girvin (2005), in a study of maltreated children in out-ofhome care, found that faulty CPS decision making in the substantiation decision may have been related to inadequate investigation processes, failure to match case documentation to legal and policy definitions, significant workload issues, pressure to unsubstantiate because of shortage of foster homes, faulty assessment tools, poor documentation of investigations, and disregard for information from others if it did not match the worker's view.

Though these and other frameworks offer advantages in their utility for studying specific aspects of child maltreatment such as the parent-child interaction or decision-making by CPS workers, the current research study adopted the DEM framework to facilitate examination and understanding of DR from a broader perspective. This approach enabled recognition and consideration of multiple social, economic, and demographic factors and interactive processes in multiple domains that could be significant in understanding DR. The DEM allows for recognition and characterization of the complexities of factors related to child maltreatment in terms of the child, family, environment, and CPS response pathways (Belsky, 1993; 
Hammond, Haegerich, \& Saul, 2009; Little \& Kantor, 2002; Whitaker, Lutzker, \& Shelley, 2005). 


\section{CHAPTER 2}

\section{REVIEW OF THE LITERATURE}

Foundational in all phases of the research process, "A research literature review is a systematic, explicit, and reproducible method for identifying, evaluating, and synthesizing the existing body of completed and recorded work produced by researchers, scholars, and practitioners" (Fink, 2010, p.3). The purpose of this review was to examine the existing literature on CPS differential responses and the relationships of community factors to the DR pathways. This report identifies the methodology used to search the literature, describes the DR model, and presents review findings related to maltreatment substantiation, maltreatment recurrence, service provision in DR, factors impacting DR, community factors and maltreatment, and gaps in the DR literature.

\section{Review Methodology}

Much of the literature on DR is not indexed in the traditional academic databases, and must be accessed via the internet and a multitude of governmental, organizational, and university websites. Table 3 presents selected websites with information and publications on DR. 
Table 3

Selected Websites for Differential Response Information and Publications

\begin{tabular}{|c|c|}
\hline Website Address & Website Sponsor \\
\hline http://www.americanhumane.org & American Humane Association \\
\hline http://www.aspe.hhs.gov & $\begin{array}{l}\text { U.S. DHHS, Office of the Assistant Secretary for Planning } \\
\text { and Evaluation }\end{array}$ \\
\hline http://www.childwelfare.gov & $\begin{array}{l}\text { Child Welfare Information Gateway, Children's Bureau, } \\
\text { Administration for Children and Families, U.S. DHHS }\end{array}$ \\
\hline http://www.childwelfarepolicy.org & Casey Family Programs \\
\hline http://www.differentialresponseqic.org & $\begin{array}{l}\text { National Quality Improvement on Differential Response in } \\
\text { Child Protective Services }\end{array}$ \\
\hline http://www.friendsnrc.org & $\begin{array}{l}\text { FRIENDS National Resource Center for Community- } \\
\text { Based Child Abuse Prevention }\end{array}$ \\
\hline http://www.iarstl.org & Institute of Applied Research, St. Louis, MO \\
\hline http://www.icpsr.umich.edu & $\begin{array}{l}\text { University of Pennsylvania, Center for Research on Youth } \\
\text { and Social Policy }\end{array}$ \\
\hline http://www.ndacan.cornell.edu & $\begin{array}{l}\text { funded by the Children's Bureau, Administration on } \\
\text { Children, Youth and Families, Administration for Children } \\
\text { and Families, U.S. DHHS }\end{array}$ \\
\hline http://www.nrccps.org & $\begin{array}{l}\text { National Resource Center for Child Protective Services; } \\
\text { funded by the Children's Bureau, Administration on } \\
\text { Children, Youth and Families, Administration for Children } \\
\text { and Families, U.S. DHHS }\end{array}$ \\
\hline http://www.state.il.us/DCFS & $\begin{array}{l}\text { State of Illinois, Department of Children and Family } \\
\text { Services }\end{array}$ \\
\hline
\end{tabular}

The methodology utilized to review the literature for this study included searches of Medline, PsycInfo, CINAHL, PubMed, and Academic Search Complete online databases using the following keywords: child abuse, child maltreatment, child welfare, child protective service, differential response, and alternative response. Searches were limited to English language and humans. This strategy 
resulted in 664 articles for initial screening. Reviewing article bibliographies resulted in additional publications for screening. Web-based search engines and resource linkages through multiple websites produced additional material. Criteria for inclusion were based on relevance, timeliness, and strength and adequacy of the material's substance. Ultimately, 173 items were selected for possible use in this review. Table 4 presents findings from selected DR publications. 
Table 4

Selected Publications Regarding Differential Response

\begin{tabular}{|c|c|c|c|c|}
\hline Author \& Year & Location & Methodology & Sample Size & Selected Findings \\
\hline $\begin{array}{l}\text { Franke, } \\
\text { Bagdasaryan, \& } \\
\text { Furman, 2011 }\end{array}$ & $\begin{array}{l}11 \text { small rural } \\
\text { counties in } \\
\text { northern California }\end{array}$ & $\begin{array}{l}\text { Comparison of } 2 \\
\text { interventions: } \\
\text { Path 1: community } \\
\text { intervention only } \\
\text { Path 2: joint CPS \& } \\
\text { community intervention } \\
\text { Cases from community } \\
\text { referral }\end{array}$ & $\mathrm{n}=90$ cases & $\begin{array}{l}\text { Case type predicted by presence of physical } \\
\text { abuse and neglect } \\
\text { Community referred cases had higher rate of } \\
\text { service receipt } \\
\text { Service delivery less differentiated by path } \\
\text { Path } 1 \text { \& Path } 2 \text { with low proportion of goal } \\
\text { accomplishment; goals most likely } \\
\text { achieved by cases receiving services }\end{array}$ \\
\hline $\begin{array}{l}\text { Lawrence, } \\
\text { Rosanbalm, \& } \\
\text { Dodge, } 2011\end{array}$ & North Carolina & $\begin{array}{l}\text { Mixed methods exploration } \\
\text { of North Carolina DR, } \\
\text { Multiple Response System } \\
\text { (MRS) } \\
9 \text { pilot \& } 9 \text { control counties } \\
\text { CPS administrative data } \\
\text { Provider focus groups } \\
\text { Caregiver phone } \\
\text { interviews, }\end{array}$ & $\begin{array}{l}\text { Provider focus } \\
\text { groups } n=450 \\
\text { Caregiver phone } \\
\text { interviews, } \\
n=223\end{array}$ & $\begin{array}{l}\text { Under MRS: } \\
\text { decline in rates of substantiations } \\
\text { decline in rates of re-assessments } \\
\text { no effect on time to case decision } \\
\text { increased number of up-front services } \\
\text { improved rapport \& family engagement } \\
\text { Implementation cost-neutral } \\
\text { Significant proportion of families receiving } \\
\text { services indicated services not very useful } \\
\text { in improving family functioning }\end{array}$ \\
\hline $\begin{array}{l}\text { Conley \& Berrick, } \\
2010\end{array}$ & $\begin{array}{l}\text { Alameda County, } \\
\text { CA }\end{array}$ & $\begin{array}{l}\text { Survival analysis } \\
\text { Quasi-experimental static- } \\
\text { group comparisons } \\
\text { Another Road to Safety } \\
\text { (ARS) treatment: home } \\
\text { visits } 9 \text { months by } \\
\text { paraprofessionals }\end{array}$ & $\begin{array}{l}\text { (ARS) treatment } \\
\text { group } \mathrm{n}=134 ; \\
\text { aged } 0-5 \text { years } \\
\text { comparison } \\
\text { group, } \mathrm{n}=511 \\
\text { Treatment: } \\
\text { home visits } 9 \\
\text { months by para- } \\
\text { professionals }\end{array}$ & $\begin{array}{l}\text { For screened out cases } \\
\text { Comparison group consisted of children } \\
\text { eligible for ARS, but not offered services } \\
\text { because of lack of program capacity } \\
\text { No differences in groups for: } \\
\text { likelihood of re-report } \\
\text { timing of maltreatment reports after ARS } \\
\text { report investigations } \\
\text { Models with demographic variables not } \\
\text { significant }\end{array}$ \\
\hline
\end{tabular}




\begin{tabular}{|c|c|c|c|c|}
\hline Author \& Year & Location & Methodology & Sample Size & Selected Findings \\
\hline $\begin{array}{l}\text { National Quality } \\
\text { Improvement Center } \\
\text { on Differential } \\
\text { Response in Child } \\
\text { Protective Services } \\
\text { (NQIC), } 2009\end{array}$ & $\begin{array}{l}\text { nationwide via } \\
\text { internet }\end{array}$ & $\begin{array}{l}103 \text { item web-based survey } \\
\text { of state CPS agencies } \\
\text { regarding DR practices, } \\
\text { models, policies, and CPS } \\
\text { structures }\end{array}$ & $\mathrm{n}=40$ & $\begin{array}{l}18 \text { states have DR - } 4 \text { not included because } \\
\text { incomplete surveys } \\
11 \text { states with statewide DR } \\
5 \text { states had DR but now defunct - expense, } \\
\text { staff turnover, leadership change, focus on } \\
\text { prevention instead of incident-based practice } \\
8 \text { states planning DR implementation in future } \\
9 \text { states no past, present, or planned DR } \\
12 \text { states did not respond to survey } \\
8 \text { states DR mandated by state statute } \\
14 \text { DR states do not substantiate } \\
\text { maltreatment in non-investigative path } \\
11 \text { DR states use risk matrices or decision trees } \\
\text { for path assignment } \\
\text { Economic hardship support, substance abuse } \\
\text { programs, \& child care services are top } 3 \\
\text { services recommended in non-investigative } \\
\text { pate }\end{array}$ \\
\hline Richardson, 2008 & & Literature review & & $\begin{array}{l}\text { Prepared by Children and Family Research } \\
\text { Center of the University of Illinois School of } \\
\text { Social Work for state of Illinois as it } \\
\text { considered DR implementation }\end{array}$ \\
\hline Conley, 2007 & $\begin{array}{l}\text { Another Road to } \\
\text { Safety (ARS) } \\
\text { Program in } \\
\text { Alameda County, } \\
\text { CA }\end{array}$ & $\begin{array}{l}\text { Critical examination of ARS } \\
\text { Program \& literature review }\end{array}$ & & $\begin{array}{l}\text { Criteria for referral to ARS: } \\
\text { Cases screened out by CPS } \\
\text { Live in targeted zip code } \\
\text { Child under the age of } 5 \text { years } \\
\text { Pregnant mother } \\
\text { ARS voluntary home visitation services } \\
\text { Targeting basic \& concrete needs } \\
\text { Paraprofessional service delivery } \\
\text { Weekly visits }>1 \text { hour over } 9 \text { months }\end{array}$ \\
\hline $\begin{array}{l}\text { Zielewski \& } \\
\text { Macomber, } 2007\end{array}$ & $\begin{array}{l}\text { One urban \& one } \\
\text { rural county each } \\
\text { for OK \& KY }\end{array}$ & $\begin{array}{l}\text { Qualitative study with semi- } \\
\text { structured interview }\end{array}$ & $n=92$ individuals & $\begin{array}{l}\text { Gaps in rural service availability for long-term, } \\
\text { inpatient substance abuse treatment \& } \\
\text { domestic violence shelters } \\
\text { Location \& quantity of rural service providers } \\
\text { present barriers \& transportation issues in } \\
\text { rural service provision }\end{array}$ \\
\hline
\end{tabular}




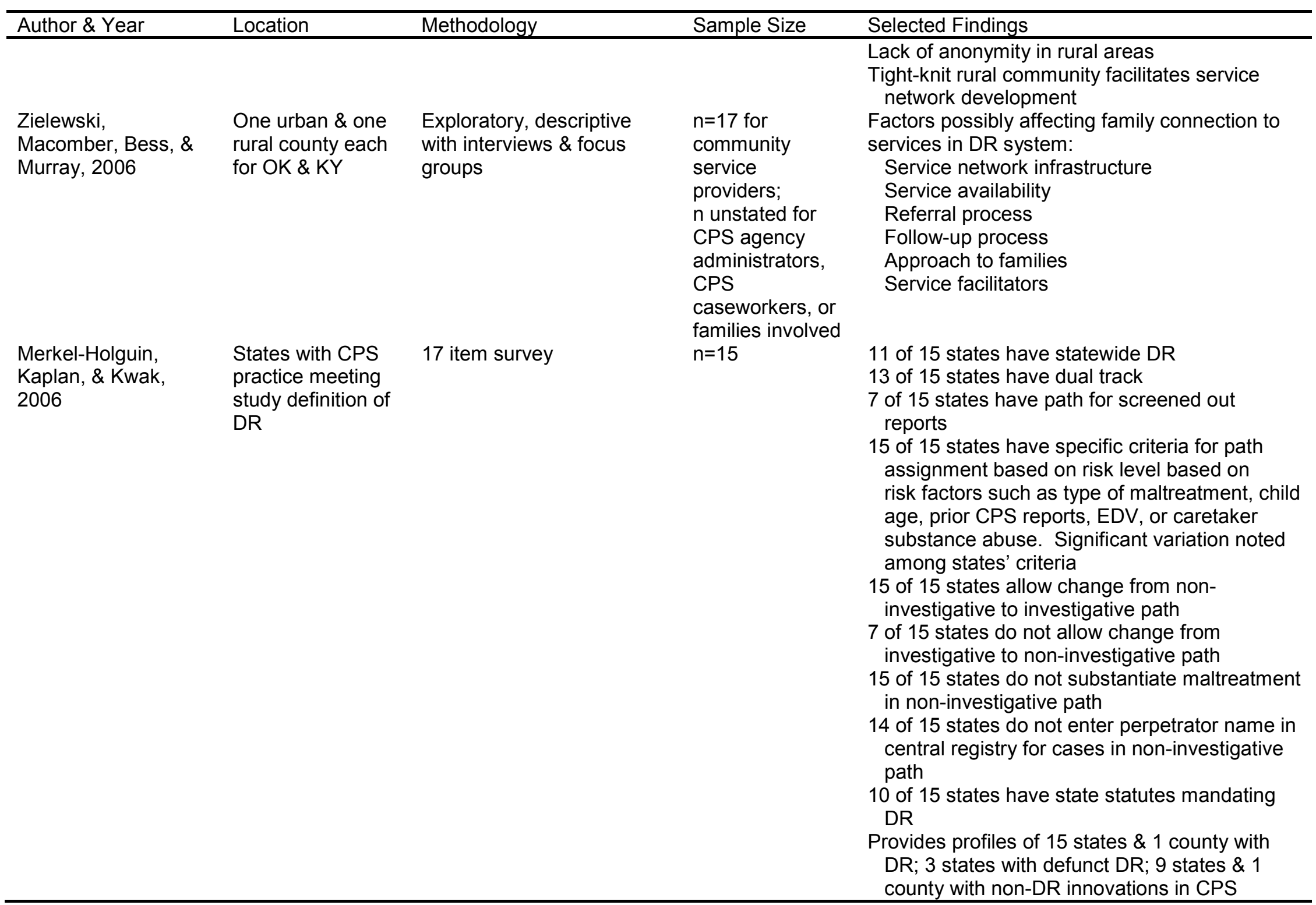




\begin{tabular}{|c|c|c|c|c|}
\hline Author \& Year & Location & Methodology & Sample Size & Selected Findings \\
\hline Loman, 2005 & $\begin{array}{l}\text { Missouri } \\
14 \text { demonstration } \\
\text { counties \& } 14 \\
\text { comparison } \\
\text { counties, }\end{array}$ & Secondary data analysis & $\begin{array}{l}\text { demonstration } \\
\mathrm{n}=3,313 ; 30 \% \\
\text { investigated } \\
\text { comparison } \\
\mathrm{n}=3,087 ; \text { all } \\
\text { investigated } \\
\text { July } 1995 \\
\text { through July } \\
1997\end{array}$ & $\begin{array}{l}\text { Initiating events: } \\
\text { Sexual abuse, } 737 \text { perpetrators } \\
\text { severe physical abuse, } 69 \text { perpetrators } \\
\text { Less severe physical abuse, } 180 \text { perpetrators } \\
738 \text { families selected from those with initiating } \\
\text { events investigated \& substantiated } \\
\text { Arrest data indicate: } \\
\text { More arrests in demonstration areas } \\
\text { More arrests in } 10 \text { day period after event } \\
\text { No difference in arrests for unrelated or } \\
\text { indirectly related offenses }\end{array}$ \\
\hline $\begin{array}{l}\text { Shusterman, } \\
\text { Hollinshead, Fluke, \& } \\
\text { Yuan, } 2005\end{array}$ & $\begin{array}{l}\text { NCANDS } 2002 \\
\text { data for } 6 \text { states } \\
\text { (KY, MN, MO, NJ, } \\
\text { OK, WY) with DR } \\
\text { \& traditional } \\
\text { paths. }\end{array}$ & Secondary data analysis & $n=318,838$ & $\begin{array}{l}\text { DR path more likely: } \\
\text { Non-professional \& school reporters } \\
\text { Lower risk cases } \\
\text { No allegation of sexual abuse } \\
\text { Older child } \\
\text { No prior CPS history } \\
\text { Living w/family; not in foster/institutional care } \\
\text { Multiple children included in report } \\
\text { History of caretaker drug abuse } \\
\text { Use of DR increasing or stable over time } \\
\text { Referrals to DR ranged from } 20 \% \text { to } 71 \% \\
\text { Those in DR path not at any greater risk for } \\
\text { subsequent reports than those in traditional } \\
\text { investigation path } \\
\text { No strong differences in DR \& investigation } \\
\text { paths for: } \\
\text { Race, ethnicity, child gender } \\
\text { Presence of family violence } \\
\text { Rate of recurrence within } 6 \text { months }\end{array}$ \\
\hline $\begin{array}{l}\text { Loman \& Siegel, } \\
2004\end{array}$ & $\begin{array}{l}\text { Missouri Family } \\
\text { Assessment \& } \\
\text { Response System } \\
\text { (FAR) } \\
14 \text { small- and } \\
\text { medium-sized } \\
\text { counties, } 14\end{array}$ & $\begin{array}{l}\text { Quasi-experimental } \\
\text { July } 1993 \text { through } \\
\text { November } 2002\end{array}$ & $\begin{array}{l}\text { demonstration } \\
n=4,110 \\
\text { comparison } \\
n=3,601\end{array}$ & $\begin{array}{l}\text { Cost-neutral implementation - large caseloads } \\
\text { \& limited resources } \\
\text { FAR families } \\
\text { Lower re-referral rates } \\
\text { Underlying risk level factors more important in } \\
\text { explaining re-referral than any differences } \\
\text { produced by the FAR approach }\end{array}$ \\
\hline
\end{tabular}




\begin{tabular}{|c|c|c|c|c|}
\hline Author \& Year & Location & Methodology & Sample Size & Selected Findings \\
\hline & $\begin{array}{l}\text { matched } \\
\text { comparison } \\
\text { counties and } \\
\text { selected zip code } \\
\text { areas in St. Louis } \\
\text { city and county } \\
\text { with matching zip } \\
\text { code areas }\end{array}$ & & & $\begin{array}{l}\text { Received greater number of services } \\
\text { Received services earlier } \\
\text { Greater number of removals \& placements for } \\
\text { FAR families in lower } 3 \text { of } 4 \text { risk levels } \\
\text { FAR most helpful for families needing short- } \\
\text { term, immediate assistance with basic needs } \\
\text { Chronic child abuse \& neglect (received } 3 \text { or } \\
\text { more referrals in } 5 \text { year study period) not } \\
\text { affected by FAR or investigation approaches }\end{array}$ \\
\hline $\begin{array}{l}\text { English, Wingard, } \\
\text { Marshall, Orme, \& } \\
\text { Orme, } 2000\end{array}$ & Washington State & $\begin{array}{l}\text { referrals diverted to } \\
\text { Community Based } \\
\text { Alternative Response } \\
\text { System (CBARS) } \\
1992 \text { to } 1995\end{array}$ & $n=1,263$ & $\begin{array}{l}\text { Washington Risk Model (WRM) used for } \\
\text { decision-making \& prioritization of services to } \\
\text { highest risk CPS cases } \\
\text { Risk levels \& severity inappropriately high for } \\
\text { some referrals to CBARS } \\
\text { Re-referral: } \\
\text { No difference in family with or without service } \\
\text { Higher rate in presence of domestic violence } \\
\text { or substance abuse } \\
\text { No difference in severity of re-referrals } \\
\text { More likely to re-refer with prior CPS history } \\
\text { No differences in placements whether services } \\
\text { received or not }\end{array}$ \\
\hline
\end{tabular}




\section{The Differential Response Model}

In the traditional medical-legal model of CPS practice (Figure 1), all screened in referrals are investigated in a process that has been viewed as adversarial, intrusive, and inappropriate for some referrals (English et al., 2000; Schene, 2001; Waldfogel, 1998). The DRM (Figure 2) of CPS practice emerged in the 1990s as an alternative to the traditional model in response to the large volume and complexity of referrals for alleged maltreatment and calls for reform of CPS practice (MerkelHolguin et al., 2006; Sawyer \& Lorbach, 2005a, 2005b; Schene, 2001; Waldfogel, 1998, Yuan, 2005). Alternative response, multiple response, family assessment response, and other names have been used as names for differential response. There is movement to focus on the DR label as it is indicative of CPS responses that treat referrals differentially based on assessment of needs in each case (CWIG, 2008; Schene, 2005). In a national study of CPS practices (U.S. DHHS, 2003), alternative responses were defined "as a formal response of the agency that assesses the needs of the child or family without requiring a determination that maltreatment had occurred or that the child is at risk of maltreatment" (U.S. DHHS, 2003, p. 3). The National Study on Differential Response in Child Welfare (MerkelHolguin et al., 2006) utilized the following as core elements in the DRM:

1. The use of two or more distinct CPS response paths, such as investigation or family assessment, for referrals that are screened in for CPS response.

2. Path assignment is based on the levels of danger, risk, prior CPS reports, report source or other case or child characteristics such as child age or type of maltreatment. Low to moderate risk cases are typically assigned to a noninvestigation path 
3. Initial path assignment can be changed if warranted by information obtained in an investigation or assessment.

4. CPS use of differential pathways is formalized in statute, policy, or protocols.

5. Acceptance of services for families in non-investigation paths is voluntary if child safety will not be compromised by refusal of services.

6. There is no formal determination, or substantiation, of maltreatment for cases in non-investigation paths, and there is no entry of a victim in a central registry.

7. In non-investigation paths, a perpetrator is not identified so there is no entry of a perpetrator in a central registry.

Central to the DRM are criteria including assessment as an alternative to investigation, collaboration with the family, family voluntariness, focus on responding to identified needs rather than victim identification and perpetrator punishment, and collaboration with community resources (Conley, 2007; CWIG, 2008; Kaplan \& Merkel-Holguin, 2008). In addition to the core criteria, values underlying the DRM have been identified (Kaplan \& Merkel-Holguin, 2008; Merkel-Holguin et al., 2006). The DRM values recognize flexibility in responding to referrals and engagement of and collaboration with the family, community members, and service organizations. In contrast to the traditional investigation path, the non-investigation path focuses on assessing family needs with engagement and encouragement rather than use of an adversarial and threatening approach. The goal is to identify needed services and support rather than to identify a victim and punish a perpetrator (Conley, 2007).

A generic DRM, as depicted in Figure 2, includes a non-investigative path in addition to the traditional CPS investigation path as a possible response to screened in referrals. Initial screening of referrals identifies levels of child maltreatment risk 
and directs high risk referrals to the investigation path and low to moderate risk referrals to alternative or non-investigative paths. The non-investigative path includes some form of family assessment in which safety, risk, and family strengths, needs, and resources are assessed. CPS DR findings may be assigned to disposition categories such as alternative response, non-victim; alternative response, victim; or maltreatment indicated or not indicated (U.S. DHHS, 2011a). CPS responses to these assessments may include determinations that no services are needed, voluntary services are recommended, or services are needed. The family may decline or agree to voluntary services. If the family refuses needed services, the case may be changed to the investigative path (Kaplan \& MerkelHolguin, 2008). In both the traditional and DR models, CPS practice is directed toward successfully meeting child safety, well-being, and permanency goals (CWIG, 2008; Kaplan \& Merkel-Holguin, 2008).

\section{Maltreatment Substantiation}

Given the DR core element that there is no formal determination or substantiation of maltreatment in the non-investigative path, it is important to understand the literature regarding child maltreatment substantiation. Even in the presence of moderate to severe harm or risk of harm, substantiation of maltreatment is unlikely to occur unless there is sufficient evidence such as documentation of medical or physical data, child reports, perpetrator admission, or eyewitness reports (Coohey, 2007; Cross \& Casanueva, 2009; Drake, 1996; Fakunmoju, 2009). Many factors influence CPS decision-making, and may have independent as well as interactive effects. Evidence of maltreatment was found to be a significant predictor 
for substantiation, regardless of maltreatment type (Cross \& Casanueva, 2009). However, the literature shows that decision-making based on evidence alone is not necessarily reflected in CPS practice (English, Marshall, Coghlan, Brummel, \& Orme, 2002). Other factors found to be significant in the substantiation decision include prior report of maltreatment (Coohey, 2007; English, et al., 2002; King, Trocme, \& Thatte, 2003), referral source (English, et al., 2002; King, et al., 2003), and parental cooperation (Coohey, 2006; King, et al., 2003). Type of maltreatment was not a significant factor (King, et al., 2003); and frequency, duration, and severity of the abuse were not found to be significant factors by Coohey (2006). Based on caseworker interviews, chronicity of abuse was found to be a significant factor in the decision to substantiate a case. Similarly, the absence of chronic maltreatment was the most important consideration in not substantiating a report (English, et al., 2002). Drug or alcohol use and prior CPS involvement were significant factors for substantiation of child maltreatment in a study of exposure to domestic violence (EDV) (Coohey, 2007).

The literature on disproportionalities in substantiation is somewhat contradictory regarding the effects of various factors such as child sex, age, race, ethnicity, and poverty. For example, substantiation was more likely for females and children aged 6 to 10 years in one study (Cross \& Casanueva, 2009), but sex was not significant in other studies (English, et al., 2002; King, et al., 2003). Hispanic children were more likely to be substantiated according to the results of an NIS-3 study (King et al., 2003); whereas a study in the state of Washington found Native Americans more likely and Caucasians less likely to be substantiated (English, et al., 
2002). In two studies, household income was associated with the substantiation decision (Cross \& Casanueva, 2009; King, et al., 2003).

In comparing maltreatment re-reporting rates for substantiated and unsubstantiated children, researchers using National Survey of Child and Adolescent Well-Being Research Group (NSCAW) data found no statistical difference in the rates (Kohl, Jonson-Reid, \& Drake, 2009). Analysis of administrative data obtained from the Missouri Division of Family Services also found little difference in maltreatment re-reporting rates for substantiated children compared to unsubstantiated children (Drake, Jonson-Reid, Way, and Chung, 2003). Similarly, another study of 806 children and their adult caregivers revealed no statistically significant differences between substantiated and unsubstantiated children for any of the outcomes measured including maltreatment recurrence, developmental skills, mental health, and behavior problems such as delinquency (Hussey, et al., 2005). The authors concluded that there is little evidence of distinction between substantiation status and unsubstantiation, and that unsubstantiated reports should not be dismissed as they do not represent the absence of maltreatment. Other studies also recognize that defining child maltreatment in terms of legal criteria and CPS investigation data is inadequate for assessing the scope and magnitude of the problem and significantly underestimates the incidence and prevalence of child maltreatment (Coohey, 2007; Cross \& Casanueva, 2009; Crume et al., 2002; Everson et al., 2008; Hussey et al., 2005; Kohl et al., 2009; Runyan et al., 2005; Sedlak et al., 2010; and Swahn et al., 2006; Theodore et al., 2005). It is possible that the use of substantiation for screening, 
investigation, or service provision may leave many actual and potential maltreatment victims unrecognized and consequently unprotected and underserved. There is some indication that substantiation may be useful in that it provides the means to invoke mandated services (Drake \& Jonson-Reid, 2000). However, the DR model makes it possible to provide services without meeting evidentiary requirements for substantiation.

\section{Maltreatment Recurrence}

In both the traditional and DR models of CPS practice, efforts are directed toward successfully meeting child safety, well-being, and permanency goals (CWIG, 2008; Kaplan \& Merkel-Holguin, 2008). Maltreatment recurrence is one outcome measure of child safety in the federal Child and Family Services Reviews (CFSR) for evaluation of CPS performance. For CFSR, maltreatment recurrence is defined as a subsequent report of substantiated maltreatment in the six months following a substantiated report of maltreatment (U.S. DHHS, 2011a). The national standard for CPS performance is $94.6 \%$ absence of maltreatment recurrence. In FFY 2010, 27 states met this standard (U.S. DHHS, 2011a).

For the 14 states reporting DR dispositions to NCANDS, five states (LA, NY, OK, WA, \& WY) did not meet the national standard in FFY 2010 (U.S. DHHS, 2011a). However, the report did not distinguish between recurrence in investigation and non-investigation paths. A study of 2002 NCANDS data from 6 DR states (KY, $\mathrm{MN}, \mathrm{MO}, \mathrm{NJ}, \mathrm{OK}, \mathrm{WY})$, found that children in the non-investigation path $(\mathrm{n}=140,072)$ did not differ significantly from children in the investigation path $(n=173,766)$ in rate of recurrence within six months (Shusterman et al., 2005). Though trajectory 
analysis showed no significant difference in re-reporting rates, proportional hazards analysis of NCANDS data for 2004 and 2005 found a very small decrease in relative risk for re-reporting for children with neglect in the non-investigation path compared to those in the investigation path (Ortiz, Shusterman, \& Fluke, 2008). Examination of North Carolina CPS administrative data from July 1996 to December 2005 in nine pilot DR and nine matched control counties showed a significantly lower rate of recurrence for the DR path (Lawrence et al., 2011). An earlier evaluation report noted declines in recurrence and re-assessments for 2000-2004, but indicated that the change could not be attributed to the DR system (Center for Child and Family Policy (CCFP), 2006).

The Family Assessment and Response (FAR) DR demonstration project in Missouri involved 14 small- and medium-sized counties, 14 matched comparison counties and selected zip code areas in St. Louis city and county with matching zip code areas (total $n=7,711$ ). Final evaluation results after five years indicated that rereferral rates were lower for the FAR group than for the control group. However, underlying risk level factors were more important in explaining re-referral than any differences produced by the FAR program (Loman \& Siegel, 2004). Impact evaluation of Minnesota's FAR project in 20 counties from 2001-2004 also showed that families $(n=1,299)$ in the matched control group were $28 \%$ more likely to have new reports and re-reports compared to families $(n=2,732)$ in the family assessment path (Siegel \& Loman, 2006). California's DR program, Another Road to Safety (ARS) has three tracks with Track 1 targeted to families in high-risk zip codes whose referrals are screened out of CPS. Survival analysis of the ARS Track 1 in Alameda 
county from May 2002 to February 2008 showed no statistically significant differences in the treatment group $(n=134)$ and the comparison group $(n=511)$ for likelihood of re-report (Conley \& Berrick, 2010). The evidence regarding maltreatment re-referral, re-reporting, and recurrence rates under DR noninvestigation paths is mixed. Further consideration and research are required to disentangle DR outcomes and paths given the methodological differences, issues of selection and surveillance bias, and limited generalizability of current studies.

\section{Service Provision and Differential Response}

Central to DRM core criteria and values is the focus on assessment of family strengths and needs and the provision of voluntary services through engagement of and collaboration with the family, community members, and service organizations (Kaplan \& Merkel-Holguin, 2008, Merkel-Holguin et al., 2006). This is in contrast to the traditional CPS model that focuses on investigation to identify and protect a victim and identify and mandate services for, and/or prosecution of, the perpetrator. Assessment outcomes in non-investigation paths may include CPS findings that no services are needed, voluntary services are recommended, or services are needed. The family may refuse or accept voluntary services, but refusal of needed services may result in a change to the investigation path (Kaplan \& Merkel-Holguin, 2008; Merkel-Holguin et al., 2006).

There are variations in services recommended and provided for families in the non-investigation path (Casey Family Programs, 2011c). The most frequently recommended services are those related to economic hardship and include assistance with housing, employment, money, and transportation (National Quality 
Improvement Center on Differential Response in Child Protective Services (NQIC, 2009). Medical and dental services are the least frequently offered and are offered in DR in only a few states (Casey Family Programs, 2011c; NQIC, 2009).

Substance abuse treatment, family counseling, child care, and parenting classes are services that are frequently offered when available in a DR state (NQIC, 2009). Some states also offered services categorized as "other" including family conferencing, domestic violence counseling, anger management, or mental health services (NQIC, 2009).

In a few studies, families in the non-investigation path received a greater number of services at greater frequency than those in the investigation path (Loman \& Siegel, 2004; Shusterman et al., 2005; Siegel \& Loman, 2006). In-home services were provided more frequently and removal/placement services less frequently to families in the non-investigation path in a study of DR in six states (Shusterman et al., 2005). For referrals with allegations of neglect, families in the non-investigation path received services at least as often as those in investigations in which neglect was substantiated (Ortiz et al., 2008). In Minnesota referrals for neglect, $54 \%$ of non-investigation path families received a specific service compared to $36 \%$ of families in the control group who were in the investigation path (Ortiz et al., 2008).

An early study of differential response in Washington State (English et al., 2000) found there was no difference in re-referral rates for families who received services and those who did not receive services. For families in the Missouri FAR non-investigation path, services needed were delivered earlier than for families in the investigation path (Loman \& Siegel, 2004). However, it was noted that the FAR 
demonstration project was affected by its cost neutral implementation resulting in large caseloads and limited resources (Loman \& Siegel, 2004). Under the North Carolina Multiple Response System (MRS) in nine pilot and nine control counties, services were also delivered earlier for families in a non-investigation path (Lawrence et al., 2011). This front-loading of services was associated with a modest decrease in the rate of re-reporting (CCFP, 2006; Lawrence et al., 2011). Of note is that a significant proportion of the NC MRS families receiving services indicated that the services were not very useful in improving family functioning (Lawrence et al., 2011). Analysis of interaction effects in the Minnesota FAR program suggested that the way families were approached was an important factor in decreasing maltreatment re-reports when controlling for services delivered (Siegel \& Loman, 2006). Findings also suggested that increased contact with CPS worker and increased length of service delivery contributed to decreased re-reporting (Siegel \& Loman, 2006).

Zielewski and Macomber (2007) noted that DR systems are based on assumptions that services are available and accessible and that families connect to services through service networks. A small study of DR in one urban and one rural county each in Oklahoma and Kentucky identified service network infrastructure, service availability, referral and follow-up processes, approaches to families, and service facilitators as factors that could affect families' connections to services (Zielewski, Macomber, Bess, \& Murray, 2006). Though follow-up of referred families rarely occurred, it was more likely to occur in families referred for intensive services. Gaps were noted in rural availability of counseling, domestic violence shelters, and 
substance abuse treatment, especially long-term residential programs. Barriers to obtaining available services included timing, location, cost, and transportation. Transportation issues were particularly acute in the rural counties (Zielewski \& Macomber, 2007; Zielewski et al., 2006).

\section{Factors Related to Differential Response}

Although state DR systems may have similar basic ideals, there are substantive differences in DR practice based on state laws, agency regulations, and local agency practices (e.g., see Table 1). In eight states DR is mandated by state statute, but the laws may not specify details such as path assignment (NQIC, 2009). Local CPS agencies may establish their own guidelines or protocols. As noted, flexibility in CPS response to referrals is an underlying value of the DRM. One of the core criteria for the DRM is path assignment based on the assessment of factors including level of danger, risk, prior CPS reports, report source or other case or child characteristics such as type of maltreatment or age of the child.

Risk assessment is a critical function of CPS agencies statutorily mandated to identify children who have been maltreated or are at risk of harm from maltreatment (CAPTA, 2010, § 5106; U.S. DHHS, 2011a). With constraints on funding and resources, risk assessment has also been used for CPS service allocation targeted to children and families with higher risk levels (Camasso \& Jagannathan, 2000; D’Andrade, Benton, \& Austin, 2005). In broader contexts, risk assessment offers screening tools for front-line personnel in health care, education, and law enforcement who may have greater exposure to potential victims or perpetrators. In 
DR systems, path assignment is dependent on the assessment of risk levels with low to moderate risk cases typically assigned to a non-investigation path.

Although various factors, such as poverty, poor parenting skills, parent substance abuse, child disability, or intimate partner violence (IPV), have been linked to increased maltreatment, there is no single factor or set of factors that has been identified as causative (Ashton, 2004; Connell, Bergeron, Katz, Saunders, \& Tebes, 2007; English et al., 2002; Leeb, Paulozzi, Melanson, Simon, \& Arias, 2008; NSCAW Research Group, 2002; Ryan, Wiles, Cash, \& Siebert, 2005; Theodore, Runyan, \& Chang, 2007). The contribution of risk factors may vary based on type of maltreatment, age, race/ethnicity, and other characteristics such as the presence of child disability or temporality issues (Algood, Hong, Gourdine, \& Williams, 2011; Black, Heyman, \& Slep, 2001; Campbell, Cook, LaFleur, \& Kennan, 2010; Connell et al., 2007; Coohey, 2007; Lee, Guterman, \& Lee, 2008; Palusci, 2011; Schumacher, Slep, \& Heyman, 2001; Slack et al., 2011; Stith et al., 2009). Table 5 presents selected examples of child maltreatment risk literature. 


\section{Table 5}

\section{Selected Publications Regarding Child Maltreatment Risk Assessment}

\begin{tabular}{|c|c|c|c|c|}
\hline Author \& Year & Location & Methodology & Sample Size & Selected Findings \\
\hline Palusci, 2011 & $\begin{array}{l}\text { National CPS } \\
\text { database } 2003-2007 \\
18 \text { states }\end{array}$ & $\begin{array}{l}\text { constructed cohort of } \\
\text { confirmed abuse or } \\
\text { neglect }\end{array}$ & $\mathrm{n}=177,568$ & $\begin{array}{l}34,211 \text { had } 2 \text { nd confirmed report 2003-2007 } \\
\text { Increased risk for 0-4 yrs of age: } \\
\text { drug/alcohol/ narcotic exposure } \\
\text { child medical problems } \\
\text { intra-familial violence } \\
\text { receiving public assistance } \\
\text { inadequate housing } \\
\text { Family support services associated with } \\
\text { decreased recurrence }\end{array}$ \\
\hline $\begin{array}{l}\text { Slack, Berger, } \\
\text { DuMont, Yang, Kim, } \\
\text { Erhard-Dietzel, \& } \\
\text { Holl, } 2011\end{array}$ & $\begin{array}{l}\text { Fragile Families and } \\
\text { Child Wellbeing } \\
\text { (FFCW) in multiple } \\
\text { large U.S. cities; } \\
\text { Healthy Families } \\
\text { New York (HFNY); } \\
\text { Illinois Families } \\
\text { Study-Child } \\
\text { Wellbeing (IFS) }\end{array}$ & $\begin{array}{l}3 \text { separate longitudinals } \\
\text { for multivariate logistic } \\
\text { regression analyses; } \\
\text { probabilistic low-income } \\
\text { families w/young children } \\
\text { FFCW is population-based } \\
\text { birth cohort. HFNY is } \\
\text { randomized control trial. } \\
\text { IFS is panel study. }\end{array}$ & $N=1622$ & $\begin{array}{l}\text { Predictive of CPS neglect determination: } \\
\text { receiving public benefits } \\
\text { seeking financial help from family } \\
\text { food pantry use } \\
\text { utility shut-offs } \\
\text { parental depression } \\
\text { child health problems } \\
\text { parental drug use } \\
\text { parental stress }\end{array}$ \\
\hline $\begin{array}{l}\text { Algood, Hong, } \\
\text { Gourdine, Williams, } \\
2011 .\end{array}$ & $\begin{array}{l}\text { Review of studies } \\
\text { from } 1980 \text { to } 2010\end{array}$ & $\begin{array}{l}\text { Parent-Child Conflict } \\
\text { Tactics Scale \& review of } \\
\text { CPS official records } \\
\text { ecological systems } \\
\text { approach } \\
\text { Focus: maltreatment of } \\
\text { children with } \\
\text { developmental disabilities }\end{array}$ & & $\begin{array}{l}\text { Risk factors: } \\
\text { child age - greater risk at younger age } \\
\text { males more likely to be abused } \\
\text { enrollment in special education - more } \\
\text { likely } \\
\text { to be abused/neglected by parent } \\
\text { physically punitive parenting } \\
\text { insecure attachment } \\
\text { parenting stress }\end{array}$ \\
\hline
\end{tabular}




\begin{tabular}{|c|c|c|c|c|}
\hline Author \& Year & Location & Methodology & Sample Size & Selected Findings \\
\hline $\begin{array}{l}\text { Campbell, Cook, } \\
\text { LaFleur, \& Keenan, } \\
2010\end{array}$ & $\begin{array}{l}\text { Longitudinal Studies } \\
\text { of Child Abuse and } \\
\text { Neglect } \\
\text { (LongSCAN) } \\
4 \text { urban sites: } \\
\text { Baltimore, Chicago, } \\
\text { Seattle, San Diego } \\
1 \text { statewide site: } \\
\text { North Carolina }\end{array}$ & $\begin{array}{l}\text { retrospective cohort of } \\
\text { high risk children at ages } \\
4 \text { to } 8 \text { years }\end{array}$ & $n=595$ & $\begin{array}{l}\text { limited social support } \\
\text { low socioeconomic status } \\
\text { Compared children with CPS investigation to } \\
\text { children without CPS investigation and found } \\
\text { no difference in modifiable risk factors. More } \\
\text { maternal depressive symptoms in the } \\
\text { investigated group }\end{array}$ \\
\hline Stith et al., 2009 & Review & $\begin{array}{l}\text { Meta-analysis review } \\
155 \text { studies of physical } \\
\text { abuse \& neglect risk } \\
\text { factors }\end{array}$ & $\begin{array}{l}155 \text { studies } \\
39 \text { risk factors } \\
\text { for physical } \\
\text { abuse }\end{array}$ & $\begin{array}{l}\text { Physical abuse strongest effect sizes for } \\
\text { parent anger/hyper-reactivity, high family } \\
\text { conflict, and low family cohesion. } \\
\text { Neglect strongest effect sizes for parental } \\
\text { stress, self-esteem. Parental competency, } \\
\text { unemployment and family size. }\end{array}$ \\
\hline $\begin{array}{l}\text { Lee, Guterman, \& } \\
\text { Lee, } 2008\end{array}$ & $\begin{array}{l}\text { Fragile Families and } \\
\text { Child Wellbeing } \\
\text { Study } \\
\text { (FFCW) in multiple } \\
\text { large U.S. cities }\end{array}$ & $\begin{array}{l}\text { Interviews } \\
\text { Proxy for physical child } \\
\text { abuse: Parent-Child } \\
\text { Conflict Tactics Scales } \\
\text { and } 2 \text { questions regarding } \\
\text { spanking in the last month }\end{array}$ & $\begin{array}{l}22 \text { risk factors } \\
\text { for neglect } \\
\mathrm{n}=1257 \\
\text { married or } \\
\text { cohabiting } \\
\text { biological } \\
\text { fathers } \\
\text { participating in } \\
\text { the FFCW }\end{array}$ & $\begin{array}{l}\text { Differential risk associations with ethnicity. } \\
\text { Father's employment/income not significant. } \\
\text { For African American fathers a cohabiting } \\
\text { relationship was linked to less physical } \\
\text { aggression and less spanking } \\
\text { Buffering effects: } \\
\text { Older paternal age at child birth }\end{array}$ \\
\hline $\begin{array}{l}\text { Connell, Bergeron, } \\
\text { Katz, Saunders, \& } \\
\text { Tebes, } 2007\end{array}$ & $\begin{array}{l}\text { Rhode Island and } \\
\text { National } \\
\text { administrative } \\
\text { dataset for } 2001 \text { - } \\
2004 \text {. }\end{array}$ & $\begin{array}{l}\text { Secondary data analysis: } \\
\text { Cox proportional hazards } \\
\text { model }\end{array}$ & $\begin{array}{l}\text { Final sample } \mathrm{n} \\
=22,584\end{array}$ & $\begin{array}{l}\text { Increased risk for re-referral to CPS: } \\
\text { age } 0-1 \text { year } \\
\text { Caucasian and ethnicity other than African } \\
\text { American or Hispanic } \\
\text { history of prior substantiated maltreatment } \\
\text { child with disability } \\
\text { history of child welfare involvement for } \\
\text { alcohol or drug use } \\
\text { family poverty or financial difficulty } \\
\text { substantiated case receiving post- }\end{array}$ \\
\hline
\end{tabular}




\begin{tabular}{|c|c|c|c|c|}
\hline Author \& Year & Location & Methodology & Sample Size & Selected Findings \\
\hline $\begin{array}{l}\text { Schumacher, Slep, } \\
\text { \& Heyman, } 2001\end{array}$ & $\begin{array}{l}\text { Review of empiric } \\
\text { literature through } \\
\text { April, } 1998\end{array}$ & Focus - child neglect & $\begin{array}{l}\text { Included } 10 \text { of } \\
619 \text { articles } \\
\text { retrieved }\end{array}$ & $\begin{array}{l}\text { investigation services } \\
\text { Very large effect size for risk related to } \\
\text { maternal-child task interaction } \\
\text { Moderate to strong effects between neglect } \\
\text { and } \\
\text { self-esteem, impulsivity, substance abuse, } \\
\text { lack of social support, daily stress } \\
\text { Other risk factors for child neglect: } \\
\text { parent-child interaction less in quantity and } \\
\text { quality } \\
\text { poverty } \\
\text { residing in urban counties }>1,000,000 \\
\text { population }\end{array}$ \\
\hline $\begin{array}{l}\text { Black, Heyman, \& } \\
\text { Slep, } 2001\end{array}$ & $\begin{array}{l}\text { Review of empiric } \\
\text { literature through } \\
\text { April, } 1998 .\end{array}$ & $\begin{array}{l}\text { Focus - child physical } \\
\text { abuse }\end{array}$ & $\begin{array}{l}\text { Included } 42 \\
\text { articles and } 4 \\
\text { books }\end{array}$ & $\begin{array}{l}\text { Moderate to strong risk for physical abuse: } \\
\text { parent history of being abused as child } \\
\text { less family social support } \\
\text { young age of parent(s) } \\
\text { paternal alcohol use } \\
\text { living in impoverished area } \\
\text { maternal distress/ } \\
\text { incompetence/depression } \\
\text { impulsivity } \\
\text { harsh parenting } \\
\text { child's behavior problems } \\
\text { negative attributions }\end{array}$ \\
\hline
\end{tabular}


Two primary risk assessment approaches are the actuarial model based on empirically validated risk factors, and the consensus model based on clinical expertise and judgment (Baird \& Wagner, 2000; D'Andrade et al., 2005). There has been debate in the literature regarding which approach is most effective for risk prediction and CPS decision-making (Baumann, Law, Sheets, Reid, \& Graham, 2005, 2006; D'Andrade et al., 2005; Johnson, 2006; Ryan et al., 2005), though there is evidence that the actuarial approach is more accurate in risk-level classification (Baird \& Wagner, 2000; D’Andrade et al., 2005). There are 11 states (see Table 1) with DR that have indicated use of risk assessment or structured decision-making tools (Casey Family Programs, 2011a). There is significant variation in the development and application of tools at state, agency, and worker levels (Kaplan \& Merkel-Holguin, 2008; NQIC, 2009).

In addition to risk, criteria for assignment to a non-investigation path vary from state to state with some states precluding non-investigation path assignment based on alleged maltreatment referral that includes criminal behavior, sexual abuse, severe physical abuse, or severe physical neglect (NQIC, 2009). Other considerations in assignment to a non-investigation path may include risk of future maltreatment, prior CPS reports, child's developmental delay or physical impairment, caregiver's mental health, domestic violence, or substance abuse (Merkel-Holguin et al., 2006; NQIC, 2009). A DR path is included for screened out referrals in only five states (FL, HI, MO, TN, WY) (NQIC, 2009).

There are significant differences in the proportion of referrals assigned to a DR path. Among states reporting CPS data to NCANDS (see Table 1), the 
proportion of children in a DR path ranged from 0.3 per cent in Wisconsin to 75.1 per cent in North Carolina (U.S. DHHS, 2011a). Children and families who received a non-investigation response were similar demographically to those who received an investigation response (Conley \& Berrick, 2010; CWIG, 2008; Shusterman et al., 2005). However, younger children were more likely to receive an investigation response (English et al., 2000; Ortiz et al., 2008; Shusterman et al., 2005). Assignment to a non-investigation path was more likely for children living at home than for children in foster care or an institutional facility (Shusterman et al., 2005). Families with more than one child included in the referral were more likely to be assigned to a non-investigation path except in Minnesota which assigns greater risk when more than one child is involved (Shusterman et al., 2005). It is unclear if the number of children in the referral was also a function of the type of maltreatment alleged as sexual and severe physical abuse referrals may include a single child and referrals for neglect may involve multiple children in the family.

The type of alleged maltreatment is a factor in distinguishing DR paths. Referrals for alleged sexual abuse were rarely assigned to a non-investigative path (Shusterman et al., 2005). Allegations of neglect, medical neglect or emotional abuse were more likely to be assigned to a non-investigation response (Shusterman et al., 2005). This is consistent with the DR core criterion that path assignment includes consideration of the severity of the allegations with the non-investigation path appropriate for referrals of less serious forms of maltreatment. However, in an early study (English et al., 2000), risk levels and severity were inappropriately high 
for some referrals to the Community Based Alternative Response System (CBARS) in Washington State.

Though history of prior CPS reports does not specifically preclude assignment to a non-investigation path, the number of prior reports and type of maltreatment in the prior report are additional considerations in path assignment (Kaplan \& MerkelHolguin, 2008). A referral with the presence of a prior CPS report is less likely to be assigned to a non-investigation path (Shusterman et al., 2005). Analysis of NCANDS data showed substantial variation among states. In Missouri and Minnesota, none of the non-investigation path children had prior CPS reports. In New Jersey, assignment to a non-investigation path was just as likely as assignment to an investigation path for children with prior CPS report. Only 7 per cent of Oklahoma and 16 per cent of Kentucky referrals with prior CPS report were assigned to the non-investigation path (Shusterman et al., 2005).

The source of referral to CPS significantly differs for DR paths. An early study in Washington State (English et al., 2000) showed educators and other social services professionals were the only referral sources for children in the CBARS path. Children in non-investigation paths were more likely to have been referred to CPS by non-professional reporters such as parents, relatives, or friends (Ortiz et al., 2008; Shusterman et al., 2005). Referrals from professional sources such as medical and nursing, legal, educational, and social work personnel were more likely to be assigned to an investigation path (English et al., 2000; Ortiz et al., 2008; Shusterman et al., 2005). 


\section{Community Factors and Maltreatment}

Community social, economic, and demographic characteristics provide indicators of the health and well-being of communities and community residents. Some of these characteristics have been associated with child maltreatment. Community has been defined variously in terms of neighborhoods, census blocks, census tracts, postal zip codes, counties, or other geopolitical boundaries. Coulton, Korbin, Chan, and Su (2001) found that social indicator values differed when comparing neighborhood based on census boundaries to neighborhood based on residents' perceptions of what constituted their neighborhood. Analyses of census tracts in Charlotte, NC found determinations of child abuse, but not child neglect, associated with census tracts having higher poverty, more single female heads of households, and larger Black population (Paulsen, 2003). In suburban Montgomery County, Ohio, census tract analyses demonstrated child maltreatment rates were associated with economic disadvantage, residential instability, and the interaction of these two variables (Ernst, 2001).

Neighborhood instability, measured by home vacancy rates and owner occupancy rates were not significant for child abuse or neglect (Paulsen, 2003). However, other studies (Coulton, Korbin, Su, \& Chow, 1995; Ernst, 2000, 2001) found residential instability associated with higher maltreatment rates.

Unemployment rate (Freisthler, Midanik, \& Gruenewald, 2004) and density of alcohol outlets were also associated with child maltreatment rates (Freisthler, 2004; Freisthler, Gruenewald, Remer, Lery, \& Needell, 2007). 
Census tracts were used to represent neighborhoods in a Los Angeles County, California, study of early care and education resources and child maltreatment in children 0 to 5 years of age (Klein, 2011). Spatial regression models showed lower rates of child maltreatment referrals and substantiations in neighborhoods with a higher percentage of 3 to 4 year olds in preschool or nursery school and lower rates of child maltreatment referrals in neighborhoods with higher availability of licensed child care. Higher rates of child maltreatment were associated with neighborhood socioeconomic disadvantage, ethnic heterogeneity, and inadequate resources for child supervision. In three California counties, spatial regression analysis of substantiated reports of child maltreatment showed higher rates of maltreatment in census-tract neighborhoods with higher levels of poverty, female heads of household, Hispanic population, and population loss (Freisthler, 2004).

Data collected in the Strong Communities for Children in the Golden Strip initiative in Greenville County, South Carolina, an urban and rural county, were analyzed using census block groups to represent neighborhoods (McDonell \& Skosireva, 2009). Neighborhood distress was a significant predictor of child physical and sexual abuse, but not a significant predictor of child neglect. Observed neighborhood characteristics predictive of substantiated child maltreatment included neighborhoods with more abandoned or boarded up dwellings, fewer indicators of cultural traditions, and fewer indicators of organized neighborhood life (McDonell \& Skosireva, 2009). 
Multivariate analysis of county-level data for lowa, considered a rural state, showed reported and substantiated child maltreatment significantly associated with rates of single-parent families, divorce, and elder abuse (Weissman, Jogerst, \& Dawson, 2003). Socioeconomic factors and presence of health care resources were not significant predictors of child maltreatment reporting or substantiation. One study focusing on neglect subtypes, race, and poverty found that community-level factors associated with poverty appeared to influence case outcomes (Jonson-Reid, Drake, \& Zhou, 2013). The majority of Black children, compared to slightly over half of White children, were from households with a history of poverty. Even with adjustment for family income, Black children in the child welfare system lived in much poorer communities than White children. There has been comparatively little investigation of the impact of community factors on CPS service decisions and outcomes.

\section{Gaps in Differential Response Literature}

Though the literature and evidence base regarding DR continue to evolve and accumulate, there are substantial gaps in the knowledge base. The effects of jurisdictional variations in DR implementation are not well described. Mixed results of modest statistical significance regarding DR indicate the need for further knowledge to identify and disentangle factors affecting DR implementation at multiple levels. It is not known whether any findings result from child, family, case, worker, community, or other factors individually or in interactive processes. It is not known whether any positive outcomes in the non-investigative DR path result from 
assignment to a non-investigative path, services provided, attributes of the interaction between family and caseworkers, or other factors.

Collaboration with community resources and services is a significant core element of the DRM. However, the role of nurses as collaborators with CPS and child welfare has not been investigated beyond the possible limited function as a member of a child protection team, normally based within an inpatient hospital facility. The literature regarding child maltreatment and nursing is primarily limited to the nurse's knowledge of signs, symptoms, and reporting requirements. Beyond mandated reporter status, there is no examination or explication of the role of nurses in DR practice models or as community resources.

Though CPS agencies are generally organized at the county level, the effects and relationships of county-level community factors to DR are largely unknown. The current study sought to fill this knowledge gap by identifying and describing countylevel factors and their relationships to CPS pathways in the DRM. These factors will be further examined to determine their significance while controlling for variables at the state, child, family, and case levels. 


\section{CHAPTER 3}

\section{METHODOLOGY}

This study used an existing national dataset from the National Child Abuse and Neglect Data System (NCANDS) for secondary data analysis. The U.S. DHHS Administration for Children and Families, via the Children's Bureau of the Administration on Children, Youth and Families (ACYF), administers the NCANDS. Federal legislation (CAPTA, 1988) established NCANDS as a national center for the collection and analysis of data voluntarily reported by the States, Puerto Rico, and the District of Columbia. Amendment to the legislation (CAPTA, 1996) requires all states receiving funds from the Federal Basic State Grant program to report the data. Results are presented in an annual report for the prior FFY, October 1 through September 30. The dataset utilized for this study contains data that were collected retrospectively for FFY 2010 (U.S. DHHS, 2011a).

State data about preventive services, funding, CPS response time, screening staff, and child fatalities are submitted in the Agency File (U.S. DHHS 2011b). The Agency File has 24 data elements and does not contain child-specific information. The NCANDS Child File (U.S. DHHS, 2011c) has 146 data elements with case-level data that is child-specific for children for whom CPS recorded a disposition or case finding. The Child File contains data elements related to report characteristics, child 
demographics, maltreatment type, child and caregiver risk factors, perpetrator information, and services provided. There were no case level data on referrals that were screened out by CPS.

Data for county-level community factors were not included in the NCANDS dataset. Data for community variables were collected at the county level, consistent with the county-level identifier in the Child File. Data on social, economic, and demographic indicators at the county level were obtained from the American Community Survey (ACS), an ongoing national survey conducted by the U.S. Census Bureau (2008). Since 2005, the ACS has sampled approximately three million addresses annually. Datasets for single year estimates are available for areas with 65,000 or more people. Beginning in 2010 , ACS three-year estimates became available for areas with 20,000 or more people; and five-year estimates became available for areas as small as census tracts and block groups (U.S. Census Bureau, 2008, 2011).

\section{Protection of Human Subjects}

As a secondary analysis of an existing administrative dataset, this study did not involve the use, recruitment, or enrollment of human subjects. Children and the subset of maltreated children represent vulnerable populations for whom the researcher must ensure protection through professional and personal accountability and adherence to the principles of respect, beneficence, non-maleficence, justice, fidelity, and veracity. The University of Missouri-Kansas City (UMKC) Institutional Review Board (IRB) ruled that this study was not subject to IRB review. The National Data Archive on Child Abuse and Neglect (NDACAN) at Cornell University, 
which houses the archived data, granted the data license for the Child File dataset. The researcher complied with all data license requirements for specific protections for data confidentiality, data security, and acknowledgement of NDACAN and the original data collectors (U.S. DHHS, 2011c).

\section{Population and Sampling}

The dataset for this study included children who were referred to CPS and screened in for a CPS response in states with a DR practice model. The sample was taken from the 14 states reporting DR dispositions to NCANDS (see Table 1). In these states for FFY 2010 there were 193,362 DR non-investigation dispositions (8,852 victims; 184,510 non-victims) and 370,898 investigation dispositions $(108,212$ substantiated; 262,686 unsubstantiated). Counties with less than 1,000 records in the Child File were de-identified by NCANDS. The following were excluded from the sample:

1. States in which DR was not established statewide by $9 / 30 / 2008$ or states which have had substantive policy or data reporting changes in since 2009. The following DR states were excluded from the sample:

Minnesota - implemented changes to Statewide Automated Child Welfare Information System (SACWIS) in FFY 2009 and FFY 2010

Nevada - piloted DR in 3 counties in 2007; implemented in all but 6 counties 2008-2009

New York - not statewide

Oklahoma - changes to SACWIS in 2010; ongoing implementation of new practice model and participation in Chadwick Trauma-Informed Systems project

Tennessee - implemented new SACWIS in 2010

Vermont - not statewide until 2010 or later 
Washington - implementation of new intake type FFY 2009 resulting in ongoing fluctuations in NCANDS reporting

Wisconsin - DR pilot in 5 counties FFY 2010

Wyoming - no DR in 6 counties \& substantive legislated changes October 2009

2. De-identified counties.

3. Records indicating child was prior victim of child maltreatment.

4. For reports including multiple children in the family, one child was randomly selected for inclusion in the analyses.

After excluding states as noted above, five states (KY, LA, MO, NC, VA) and 98 counties remained for inclusion in the analyses. Table 6 contains information about these states, the number of counties for analyses, and the number of children in the DR and traditional paths.

Table 6

U.S. States with CPS Differential Responses for Inclusion in Analyses

\begin{tabular}{|c|c|c|c|c|c|c|c|}
\hline State & $\begin{array}{l}\text { 1st } \\
\text { Year } \\
\text { DR }\end{array}$ & $\begin{array}{l}\text { Number } \\
\text { Counties } \\
\text { Available } \\
\text { For } \\
\text { Analysis } \\
\end{array}$ & $\begin{array}{l}\text { Total } \\
\text { Number } \\
\text { in DR } \\
\text { path } \\
\end{array}$ & $\begin{array}{l}\text { Total } \\
\text { Number in } \\
\text { Traditional } \\
\text { Investigation } \\
\text { Path } \\
\end{array}$ & $\begin{array}{l}\text { Paths for } \\
\text { Screened } \\
\text { In Reports }\end{array}$ & $\begin{array}{l}\text { Path for } \\
\text { Screened } \\
\text { Out } \\
\text { Reports } \\
\end{array}$ & $\begin{array}{l}\text { Risk/ } \\
\text { SDM } \\
\text { tool to } \\
\text { Assign } \\
\text { Path } \\
\end{array}$ \\
\hline Kentucky & 2001 & 15 & 14,223 & 34,918 & 4 & No & Yes \\
\hline Louisiana & 1999 & 12 & 2,528 & 19,294 & 2 & & SDM \\
\hline Missouri & 1994 & 12 & 25,461 & 25,508 & 2 & Yes & Yes \\
\hline $\begin{array}{l}\text { North } \\
\text { Carolina }\end{array}$ & 2001 & 41 & 49,654 & 16,482 & 2 & No & Yes \\
\hline Virginia & 2002 & 18 & 25,514 & 9,482 & 2 & No & Yes \\
\hline TOTALS & & 98 & 117,380 & 105,684 & & & \\
\hline
\end{tabular}

Note. Sources: Casey Family Programs, 2011a; NQIC 2009; U.S. DHHS, 2011a. 


\section{Measures}

The NCANDS Child File report disposition data were used to identify cases for the outcome (dependent) variable, CPS response path, with binary categories of AR (non-investigative) path and the non-AR (investigative) path. Records identified in the NCANDS Child File with report dispositions of $A R$ victim or AR non-victim were combined and assigned to the AR path. Records in all other NCANDS dispositions were assigned to the non-AR path. Multiple NCANDS variables were removed from study analyses because there were insufficient data reported, or very large percentages of data values were reported as missing or unknown. Variables remaining for analysis included two state-level, twelve county-level, and six childlevel variables. Variables included in study analyses are presented in Table 7. 
Table 7

Variables Included in the Study

\begin{tabular}{|c|c|c|c|c|}
\hline Variable & Type & $\begin{array}{l}\text { Level of } \\
\text { Measurement }\end{array}$ & $\begin{array}{l}\text { Data } \\
\text { Source } \\
\end{array}$ & $\begin{array}{l}\text { Variable } \\
\text { Code Name } \\
\end{array}$ \\
\hline $\begin{array}{l}\text { CPS Response Path } \\
\text { AR or non-AR }\end{array}$ & dependent & categorical & NCANDS & RptDispRECODE \\
\hline $\begin{array}{l}\text { Child Characteristics } \\
\text { Child ID } \\
\text { Age } \\
\text { Sex } \\
\text { Race }\end{array}$ & $\begin{array}{l}\text { identification } \\
\text { independent } \\
\text { independent } \\
\text { independent }\end{array}$ & $\begin{array}{l}\text { categorical } \\
\text { categorical } \\
\text { categorical }\end{array}$ & $\begin{array}{l}\text { NCANDS } \\
\text { NCANDS } \\
\text { NCANDS } \\
\text { NCANDS }\end{array}$ & $\begin{array}{l}\text { ChID } \\
\text { ChAgeREC5 } \\
\text { ChSexREC } \\
\text { ChRaceREC3 }\end{array}$ \\
\hline $\begin{array}{l}\text { Report Characteristics } \\
\text { Report ID } \\
\text { State of report } \\
\text { County of report } \\
\text { Report source } \\
\text { Number children in report } \\
\text { Maltreatment type }\end{array}$ & $\begin{array}{l}\text { identification } \\
\text { location } \\
\text { location } \\
\text { independent } \\
\text { independent } \\
\text { independent }\end{array}$ & $\begin{array}{l}\text { categorical } \\
\text { categorical } \\
\text { categorical }\end{array}$ & $\begin{array}{l}\text { NCANDS } \\
\text { NCANDS } \\
\text { NCANDS } \\
\text { NCANDS } \\
\text { NCANDS } \\
\text { NCANDS }\end{array}$ & $\begin{array}{l}\text { RptID } \\
\text { StaTerr } \\
\text { RptFIPSrec } \\
\text { RptSrcREC2 } \\
\text { nChildRec3 } \\
\text { ChMalREC4 }\end{array}$ \\
\hline $\begin{array}{l}\text { County-Level Factors } \\
\text { Number cases in county } \\
\text { Households with public } \\
\text { assistance } \\
\text { Household income } \\
\text { Housing Vacancy } \\
\text { Unemployment } \\
\text { Child Poverty } \\
\text { Persons with HS, equiv. } \\
\text { Single-parent households } \\
\text { Population age }<18 \text { years } \\
\text { Race = White } \\
\text { Race = Black } \\
\text { Race = not Black or White }\end{array}$ & $\begin{array}{l}\text { independent } \\
\text { independent } \\
\text { independent } \\
\text { independent } \\
\text { independent } \\
\text { independent } \\
\text { independent } \\
\text { independent } \\
\text { independent } \\
\text { independent } \\
\text { independent } \\
\text { independent }\end{array}$ & $\begin{array}{l}\text { categorical } \\
\text { categorical } \\
\text { categorical } \\
\text { continuous } \\
\text { continuous } \\
\text { continuous } \\
\text { continuous } \\
\text { continuous } \\
\text { continuous } \\
\text { continuous } \\
\text { continuous } \\
\text { categorical }\end{array}$ & $\begin{array}{l}\text { NCANDS } \\
\text { ACS } \\
\text { ACS } \\
\text { ACS } \\
\text { ACS } \\
\text { ACS } \\
\text { ACS } \\
\text { ACS } \\
\text { ACS } \\
\text { ACS } \\
\text { ACS } \\
\text { ACS }\end{array}$ & $\begin{array}{l}\text { NumCasesREC } \\
\text { HHpubAsistREC } \\
\text { HHincomeREC } \\
\text { HsgVacRate } \\
\text { UnemployRate } \\
\text { ChPovRate } \\
\text { EducHSorEquivRate } \\
\text { HHsingIParentRate } \\
\text { Pop0_17yrsRate } \\
\text { RaceWhiteRate } \\
\text { RaceBlackRate } \\
\text { RaceElseRate }\end{array}$ \\
\hline $\begin{array}{l}\text { State-Level Variables } \\
\text { Years since DR start } \\
\text { Intake level: central or local }\end{array}$ & $\begin{array}{l}\text { independent } \\
\text { independent }\end{array}$ & $\begin{array}{l}\text { categorical } \\
\text { categorical }\end{array}$ & $\begin{array}{l}\text { NQIC } \\
\text { NQIC }\end{array}$ & $\begin{array}{l}\text { StYrREC } \\
\text { IntakeLev }\end{array}$ \\
\hline
\end{tabular}

Note. $\mathrm{AR}=$ Alternative Response; $\mathrm{HS}=$ high school; equiv. = equivalent; NCANDS = National Child Abuse and Neglect Data System; ACS = American Community Survey; NQIC = National Quality Improvement Center on Differential Response in Child Protective Services; DR = Differential Response. 
Predictor (independent) variables within the intrapersonal domain included child age (categorized into five levels), sex (male, female), and child race (Black, White, Other). The number of children included in the report was categorized into three levels $(1,2,3$ or more $)$. Type of maltreatment was categorized into four levels (physical, neglect or deprivation, sexual, or other). The NCANDS dataset allows for assignment of up to four maltreatment types from the child victim's record. The maltreatment type appearing first in the record is assigned to NCANDS variable Child maltreatment type 1 ; the second type in the record is assigned to NCANDS variable child maltreatment type 2; and so on through up to four maltreatment types. The NCANDS variable child maltreatment type 1 was used for the study variable, maltreatment type. Cases identified in NCANDS data as psychological or emotional maltreatment, or unknown were assigned to the other level. Report source was categorized into mandated reporter or non-mandated reporter. Mandated reporters included persons required by law to report suspected child maltreatment, such as workers in social services, health, education, and legal professions. Non-mandated reporters not required by law to report suspected child maltreatment, included persons such as parents, relatives, friends, neighbors, anonymous persons, and other or unknown persons.

Within the community (exosystem) domain, county variables included number of cases in the county $(<1000$ or $\geq 1000)$, median household income $(<\$ 45,000$ or $\geq \$ 45,000)$, households receiving public assistance $(<25 \%$ or $\geq 25 \%)$, and race (Black, White, Other). Additional county variables included housing vacancy, unemployment, child poverty, single parent households, population from zero to 
seventeen years, and persons with high school or equivalent diploma. Variables at the state level included number of years since implementation of DR $(<10$ or $\geq 10$ years) and whether intake level was central (reports received in a centralized office at the state level) or non-central (reports received in the county CPS office).

\section{Data Analysis}

The first step in the analysis strategy for these two massive datasets was to construct a single dataset with study variables and sample. Case selection and exclusion criteria were applied to the NCANDS dataset. Variables were recoded to facilitate analysis and interpretation of results. The NCANDS Report ID variable provided identification of reports involving multiple children in a single report. When more than one child in a family was the subject of a report, one child was randomly selected for inclusion in the analyses to allow analyses congruent with the child level of the NCANDS dataset.

Significantly more preparation was required to construct a single dataset from the ACS data files. There were separate ACS data files for each variable in each of the five states. Multiple steps were required to construct a dataset for each state with the data for that state. The five state datasets were merged into one dataset with all ACS variables and data. Multiple calculations were required to assess the reliability of the estimates for the 2008-2010 ACS 3-Year data and to transform and aggregate coefficients from the 90 per cent confidence level reported by ACS to the 95 per cent confidence level for this study. The NCANDS and ACS datasets were then merged to produce one data file for analysis containing 62,499 cases, 98 counties, and five states. 
Following data preparation and construction of the study dataset, exploratory data analysis provided preliminary information about the data and sample. Univariate and bivariate analyses provided additional information. However, IBM SPSS Statistics (Version 22) for Windows was unable to process some nonparametric correlational measures because of the large number of cases in the dataset. Pearson correlations for the entire dataset were completed without any problem. A randomly selected small subgroup was used to run Pearson and Spearman correlations. In comparing the subgroup results, there was minimal difference, $+/-0.03$, between the two measures. Based on this, the Pearson $r$ results for the entire dataset are reported for the study in this manuscript. With CPS response path $(A R$, non- $A R)$ as the only outcome, or dependent variable (DV), and multiple independent variables (IV) measured at the categorical or continuous level, statistical techniques were limited (Mertler \& Vannatta, 2005). Binary logistic regression was useful for examining variable relationships in a single level, but did not address data nested in multiple levels. Further analysis of the data required multilevel modeling (MLM) techniques for hierarchical data with the binary outcome variable of CPS response path (AR, non-AR path).

Using the Generalized Linear Mixed Models (GLMM) procedure in IBM SPSS (Version 22) allowed specification of nested levels with the child level (microlevel 1) nested within the county level (macrolevel 2), and child and county levels nested within the state level (macrolevel 3). An unconditional (null) model containing only intercepts was built and examined to assess variance and the need for continuing the MLM procedure. Variabilities of less than $5 \%$ demonstrate insufficient variation 
to make the MLM procedure worthwhile (Heck, Thomas, \& Tabata, 2010). Multiple additional three-level models were constructed and examined for model fit, classification accuracy, variance, and significance of predictor variables. 


\section{CHAPTER 4}

\section{RESULTS}

The final dataset included 62,499 cases, 98 counties, and five states. Multiple NCANDS variables were removed from further analysis because there was insufficient data reported, or very large percentages of data values were reported as missing or unknown. For example, values for perpetrator variables were reported in less than $10 \%$ of the cases: age $9.3 \%$, sex $8.9 \%$, race $0 \%$, ethnicity $0 \%$, and perpetrator relationship to the child $6.9 \%$. Child risk and caretaker risk variables were also removed as values were reported in less than $25 \%$ and $20 \%$ of the cases respectively. Variables remaining for analysis (see Table 7) included two state-level, twelve county-level, and six child-level variables. It is essential to correctly identify measurement level of variables for the advanced multilevel modeling techniques in SPSS (Version 22) in which categorical variables are called factors and continuous variables are called covariates.

Table 8 presents demographic and descriptive results for categorical variables and continuous variables, including case and county frequencies for each state. Of particular note is that North Carolina had $41.8 \%(n=41)$ of the counties, but only $10.1 \%(n=6,334)$ of the cases. There were nearly equal numbers of cases in the AR path $(50.0 \%, n=31,277)$ and the non-AR path $(50.0 \%, n=31,222)$. Reports with only one child reported accounted for $60.9 \%(n=38,077)$ of the cases. For 
reports with multiple children reported $(n=24,422)$, one child was randomly selected for inclusion in the study. Children under one year of age $(n=6,961)$ and ages one through three years $(n=12,645)$ were $31.3 \%$ of the cases. Demographics included slightly more males $(50.1 \%, n=31,321)$ than females $(49.9 \%, n=31,178)$ and more White $(57.0 \%, n=35,623)$ than Black $(34.0 \%, n=21,278)$ or Other $(9.0 \%, n=5,598)$ children. The most frequent type of maltreatment reported was neglect or deprivation $(41.0 \%, n=25,623)$, compared to physical $(16.6 \%, n=10,401)$, sexual $(4.5 \%, n=2,818)$, and other forms of abuse $(37.9 \%, n=23,657)$ including medical neglect, psychological/emotional maltreatment, and other unspecified types of maltreatment. Mandated reporters generated $61.0 \%(n=38,129)$ of the reports compared to $39.0 \%(n=24,370)$ generated by non-mandated reporters. 
Table 8

Demographics and Descriptives for Study Variables

\begin{tabular}{|c|c|c|}
\hline Variable & $\mathrm{n}$ & $\begin{array}{l}\% \text { of } \\
\text { total } n\end{array}$ \\
\hline \multicolumn{3}{|c|}{ Dependent: CPS Response Path } \\
\hline non-AR & 31,222 & 50.0 \\
\hline AR & 31,277 & 50.0 \\
\hline \multicolumn{3}{|l|}{ Factors (categorical) } \\
\hline \multicolumn{3}{|l|}{ Child age } \\
\hline under 1 year & 6,961 & 11.1 \\
\hline $1-3$ years & 12,645 & 20.2 \\
\hline 4-7 years & 14,733 & 23.6 \\
\hline $8-12$ years & 14,593 & 23.3 \\
\hline 13 years and older & 13,567 & 21.7 \\
\hline \multicolumn{3}{|l|}{ Child sex } \\
\hline Male & 31,321 & 50.1 \\
\hline Female & 31,178 & 49.9 \\
\hline \multicolumn{3}{|l|}{ Child race } \\
\hline Black & 21,278 & 34.0 \\
\hline White & 35,623 & 57.0 \\
\hline Other & 5,598 & 9.0 \\
\hline \multicolumn{3}{|c|}{ Number children in the reporta } \\
\hline 1 & 38,077 & 60.9 \\
\hline 2 & 13,854 & 22.2 \\
\hline $3+$ & 10,568 & 16.9 \\
\hline \multicolumn{3}{|l|}{ Maltreatment type } \\
\hline Physical & 10,401 & 16.6 \\
\hline Neglect or deprivation & 25,623 & 41.0 \\
\hline Sexual & 2,818 & 4.5 \\
\hline Other & 23,657 & 37.9 \\
\hline \multicolumn{3}{|l|}{ Report source } \\
\hline Non-mandated & 24,370 & 39.0 \\
\hline Mandated & 38,129 & 61.0 \\
\hline \multicolumn{3}{|l|}{ Number of cases in state } \\
\hline Kentucky & 10,045 & 16.1 \\
\hline Louisiana & 10,669 & 17.1 \\
\hline Missouri & 18,863 & 30.2 \\
\hline North Carolina & 6,334 & 10.1 \\
\hline Virginia & 16,588 & 26.5 \\
\hline \multicolumn{3}{|l|}{ Number of counties in state } \\
\hline Kentucky & 15 & 15.3 \\
\hline Louisiana & 12 & 12.25 \\
\hline Missouri & 12 & 12.25 \\
\hline North Carolina & 41 & 41.8 \\
\hline Virginia & 18 & 18.4 \\
\hline \multicolumn{3}{|l|}{ Number cases in county } \\
\hline$<1000$ & 30,631 & 49.0 \\
\hline $1000+$ & 31,868 & 51.0 \\
\hline
\end{tabular}




\begin{tabular}{|c|c|c|c|c|}
\hline Variable & & $\mathrm{n}$ & $\begin{array}{l}\% \text { of } \\
\text { total } n\end{array}$ & \\
\hline \multicolumn{5}{|l|}{$\begin{array}{l}\text { Households with public } \\
\text { assistance }\end{array}$} \\
\hline$<25 \%$ & & 28,066 & 44.9 & \\
\hline $25+\%$ & & 34,433 & 55.1 & \\
\hline \multicolumn{5}{|l|}{ Household income } \\
\hline$<\$ 45000$ & & 25,960 & 41.5 & \\
\hline$\$ 45000+$ & & 36,539 & 58.5 & \\
\hline Administrative level of intake & & 33,591 & 53.7 & \\
\hline not central & & 2092 & 367 & \\
\hline central & & $\begin{array}{l}22, y<2 \\
39,577\end{array}$ & 63.3 & \\
\hline \multicolumn{5}{|l|}{ Number of years since DR start } \\
\hline$<10$ years & & 32,967 & 52.7 & \\
\hline $10+$ years & & 29,532 & 47.3 & \\
\hline Covariates (continuous) & Minimum & Maximum & Mean & SD \\
\hline Housing vacancy & 4.22 & 40.98 & 10.56 & 3.92 \\
\hline Unemployment & 3.12 & 9.09 & 5.41 & 1.37 \\
\hline Child poverty & 3.58 & 44.48 & 20.48 & 9.21 \\
\hline Persons with HS or equivalent & 13.54 & 41.82 & 28.30 & 6.17 \\
\hline Single parent households & 15.34 & 65.38 & 36.51 & 11.67 \\
\hline Population age 0 to 17 year & 16.94 & 30.54 & 24.16 & 2.31 \\
\hline White race & 31.19 & 97.37 & 71.83 & 15.96 \\
\hline Black race & .49 & 60.23 & 20.56 & 14.99 \\
\hline Not Black or White race & 2.07 & 46.91 & 9.86 & 6.44 \\
\hline
\end{tabular}

Note. CPS = Child protective services; $A R=$ alternative response; $D R=$ differential response; $\mathrm{SD}=$ standard deviation; $\mathrm{HS}=$ high school.

aFor reports with multiple children, one child was randomly selected for inclusion in the analyses.

The number of cases per county ranged from 50 to 4,060 with $51.0 \%$ $(n=31,868)$ in counties with more than 1,000 cases. Median household income ranged from $\$ 29,041$ to $\$ 116,802$ with $41.5 \%(n=25,960)$ of cases from counties with median household income of less than $\$ 45,000$. Counties with more than $25 \%$ of 
the households with children receiving public assistance comprised $55.1 \%$ $(n=34,433)$ of the cases. County demographics had divergent levels of unemployment (3.12-9.09\%), child poverty (3.58-44.48\%), housing vacancy (4.22$40.98 \%)$, and education at the high school or equivalent level (13.54-41.82\%). County demographics were more widely divergent in levels for single parent households (15.34-65.38\%) and race (Black, 0.49-60.23\%; White, 31.19-97.37\%; non-Black, non-White, 2.07-46.91\%).

Bivariate analysis showed multiple variable correlations significant at the $p<.01$ level, with many very weak relationships $(r<.200)$. Child poverty was strongly associated with single parent households ( $r=.903)$, unemployment level $(r=.670)$, housing vacancy levels ( $r=.757)$, households with public assistance $(r=.784)$, and median household income ( $r=-.706)$. Housing vacancy showed moderate to strong relationships to other indicators (single parent housing, $r=.677$; unemployment, $r=.625$; households with public assistance, $r=.547$; Black race, $r=.476$; White race, $r=-.358$, and median household income, $r=-.492$ ). Significant relationships for unemployment paralleled those of housing vacancy, but at slightly lower levels (single parent housing, $r=.623$; households with public assistance, $r=.467$; Black race, $r=.427$; White race, $r=-.314$, and household income, $r=-.442$ ).

County-level variance in the unconditional model suggested significant $(p<.001)$ variability between counties. Calculation of intraclass correlation (ICC) further suggested that approximately $10.33 \%$ of variability in the outcome variable $(A R$, non-AR) was between counties. This demonstrated support for the use of MLM procedures to account for variabilities. Variance components for the unconditional 
(null) model, the model with all predictors entered, and the final model are presented

in Table 9. Intraclass correlation in the final model suggested that approximately $12.30 \%$ of variability in the outcome variable $(A R$, non- $A R)$ was between counties.

Table 9

Variance Components

\begin{tabular}{|c|c|c|c|}
\hline Effect & $\begin{array}{c}\text { MODEL 1: } \\
\text { Unconditional } \\
\text { Estimate }(\mathrm{SE})[\mathrm{Cl}]\end{array}$ & $\begin{array}{c}\text { MODEL 2: } \\
\text { All Predictors } \\
\text { Estimate (SE)[Cl] }\end{array}$ & $\begin{array}{c}\text { FINAL } \\
\text { MODEL } \\
\text { Estimate (SE)[Cl] }\end{array}$ \\
\hline \multicolumn{4}{|l|}{ Residual Variance } \\
\hline Level 1 (micro: child-level)a & 1.000 & 1.000 & 1.000 \\
\hline \multicolumn{4}{|l|}{ Random Variance (Intercept) } \\
\hline Level 2 (macro: county-level) ${ }^{\mathrm{b}}$ & $\begin{array}{c}0.550^{*}(0.089) \\
{[0.401,0.755]}\end{array}$ & $\begin{array}{l}0.611^{*}(0.105) \\
{[0.437,0.855]}\end{array}$ & $\begin{array}{c}0.588^{*}(0.097) \\
{[0.426,0.811]}\end{array}$ \\
\hline Level 3 (macro: state-level) ${ }^{c}$ & $\begin{array}{r}1.483(1.075) \\
{[0.358,6.143]}\end{array}$ & $\begin{array}{c}0.717(0.785) \\
{[0.084,6.137]}\end{array}$ & $\begin{array}{r}0.901(0.767) \\
{[0.170,4.782]}\end{array}$ \\
\hline Prediction Accuracy & $69.4 \%$ & $74.3 \%$ & $74.4 \%$ \\
\hline \multicolumn{4}{|l|}{ Intraclass Correlation } \\
\hline Level 2 - Between Counties & 0.1033 & 0.1323 & 0.1230 \\
\hline Level 3 - Between States & 0.2786 & 0.1553 & 0.1885 \\
\hline AICC & $284,236.618$ & $315,908.983$ & $315,678.569$ \\
\hline \multicolumn{4}{|c|}{$\begin{array}{l}\text { Note. SE = standard error; } p=\text { significance; } \mathrm{Cl}=\text { confidence interval; AICC = Akai } \\
\text { Criterion Corrected } \\
\text { aCovariance structure: scaled identity; subject specification: none } \\
\text { bCovariance structure: variance components; subject specification: State }{ }^{*} \text { County } \\
\text { cCovariance structure: variance components; subject specification: State } \\
{ }^{*} p<.001\end{array}$} \\
\hline
\end{tabular}

The $F$ statistic reported in SPSS (Version 22) MLM fixed effects output provides the significance of the independent variables in predicting the outcome variable, CPS response path. Examination of MLM fixed effects (Table 10) showed 
multiple nonsignificant $(p>.05)$ variables in Model 2 , the initial three-level model with all predictors entered. Multiple models eliminating nonsignificant variables were examined. Nonsignificant variables were retained in some models in attempts to improve model fit. Some variables were significant in some models, but not in other models. The final model contained variables significant $(p<.05)$ in predicting CPS response path, including all child variables (report source, maltreatment type, child age, race, and number of children in the report) except child sex, four county variables (housing vacancy, unemployment, child poverty, and households with public assistance), and one state variable (number of years since DR started). 
Table 10

Multilevel Model Analysis: Fixed Effects Statistics

\begin{tabular}{lrrrrr}
\hline Source & Model 2 & & Final Model & \\
\cline { 2 - 4 } & $\mathrm{F}$ & Sig. & $\mathrm{F}$ & Sig. \\
\hline Corrected Model & & & & \\
& 574.08 & $<.001$ & 620.17 & $<.001$ \\
Level 1 (micro: child-level) & & & & \\
Report source & 6.76 & .009 & 6.77 & .009 \\
Maltreatment type & 492.85 & $<.001$ & 503.47 & $<.001$ \\
Number children in the reporta & 5.08 & .006 & 5.07 & .006 \\
Child age & 356.53 & $<.001$ & 359.49 & $<.001$ \\
Child sex & 0.09 & .332 & & \\
Child race & 5.80 & .003 & 5.99 & .003 \\
& & & & \\
Level 2 (macro: county-level) & & & & \\
Number cases in county & 0.10 & .752 & & \\
Housing vacancy & 13.11 & $<.001$ & 15.40 & $<.001$ \\
Unemployment & 3.72 & .054 & 8.68 & .003 \\
Child poverty & 9.55 & .002 & 7.36 & .007 \\
Households with public assistance & 3.60 & .058 & 6.46 & .011 \\
HS diploma or equivalent & 15.44 & $<.001$ & & \\
Single parent households & 1.44 & .230 & & \\
Population age 0 to 17 years & 1.09 & .296 & & \\
White race & 20.33 & .154 & & \\
Black race & 1.38 & .241 & & \\
Not Black or White race & 1.37 & .241 & & \\
Median Household income & 0.03 & .855 & & & \\
Level 3 (macro: state-level) & & & & \\
Administrative level of intake office & 8.02 & .005 & & \\
Number of years since DR start & 2.62 & .105 & 4.79 & \\
& & & & \\
\hline Note.Sig. & & & & \\
\hline
\end{tabular}

Note.Sig. = significance; $\mathrm{HS}=$ high school; $\mathrm{DR}=$ differential response. $\mathrm{F}=$ statistic for fixed effects significance testing in binomial probability distribution with logit link function.

aFor reports with multiple children, one child was randomly selected for inclusion in the analyses.

Fixed coefficient statistics in the final model (Table 11) provide estimates of influence the independent variables have on the outcome variable. 
Table 11

Multilevel Model Analysis: Fixed coefficients for the Final Model

\begin{tabular}{|c|c|c|c|c|c|}
\hline Parameter & Coeff. & SE & Sig. & OR & $95 \% \mathrm{Cl}$ for OR \\
\hline Intercept & -0.59 & 1.06 & .579 & 0.55 & {$[0.07,4.42]$} \\
\hline \multicolumn{6}{|l|}{ Level 1 (micro: child-level) } \\
\hline \multicolumn{6}{|l|}{ Report source } \\
\hline Non-mandated reporter & referent & & & & \\
\hline Mandated reported & -0.37 & 0.14 & .009 & 0.69 & {$[0.52,0.91]$} \\
\hline \multicolumn{6}{|l|}{ Maltreatment type } \\
\hline Physical & referent & & & & \\
\hline Neglect or deprivation & 0.87 & 0.49 & .072 & 2.40 & {$[0.92,6.22]$} \\
\hline Sexual & -4.17 & 0.80 & $<.001$ & 0.01 & {$[0.01,0.07]$} \\
\hline Other & 2.71 & 1.90 & 153 & 15.11 & {$[0.36,627.80]$} \\
\hline \multicolumn{6}{|l|}{ Number children in the report ${ }^{\mathrm{a}}$} \\
\hline 1 & referent & & & & \\
\hline 2 & -0.02 & 0.05 & .626 & 0.97 & {$[0.88,1.08]$} \\
\hline $3+$ & -0.19 & 0.08 & .021 & 0.83 & {$[0.71,0.97]$} \\
\hline \multicolumn{6}{|l|}{ Child age } \\
\hline under 1 year & referent & & & & \\
\hline $1-3$ years & -0.01 & 0.04 & .902 & 0.99 & {$[0.91,1.08]$} \\
\hline 4-7 years & 0.36 & 0.09 & $<.001$ & 1.43 & {$[1.20,1.70]$} \\
\hline $8-12$ years & 0.68 & 0.11 & $<.001$ & 1.98 & {$[1.58,2.48]$} \\
\hline 13 years and older & 0.53 & 0.17 & .002 & 1.70 & {$[1.21,2.39]$} \\
\hline \multicolumn{6}{|l|}{ Child race } \\
\hline Black & referent & & & & \\
\hline White & 0.15 & 0.05 & .005 & 1.16 & {$[1.05,1.29]$} \\
\hline Other & 0.19 & 0.08 & .017 & 1.20 & {$[1.03,1.40]$} \\
\hline \multicolumn{6}{|l|}{ Level 2 (macro: county-level) } \\
\hline Housing vacancy & -0.03 & 0.01 & $<.001$ & 0.97 & {$[0.95,0.98]$} \\
\hline Unemployment & -0.18 & 0.06 & .003 & 0.84 & {$[0.74,0.94]$} \\
\hline Child poverty & 0.02 & 0.01 & .007 & 1.02 & {$[1.00,1.03]$} \\
\hline \multicolumn{6}{|c|}{ Households with public assistance } \\
\hline$<25 \%$ & referent & & & & \\
\hline $25+\%$ & 1.02 & 0.14 & $<.001$ & 2.78 & {$[2.10,3.68]$} \\
\hline \multicolumn{6}{|l|}{ Level 3 (macro: state-level) } \\
\hline Number of years since DR & & & & & \\
\hline$<10$ years & referent & & & & \\
\hline $10+$ years & -2.65 & 1.21 & .029 & 0.07 & {$[0.01,0.76]$} \\
\hline
\end{tabular}


Results indicated that reports by mandated reporters were $31.3 \%$ less likely to be in the AR path than reports by non-mandated reporters. Compared to cases of physical maltreatment, the AR path was $98.5 \%$ less likely for cases of sexual abuse, 15.1 times more likely for cases of other maltreatment types, and 2.4 times more likely for cases of neglect or deprivation. Reports with three or more children in the case report were $17 \%$ less likely to be AR path than case reports with only one child. When compared to children under one year of age, AR path was more likely for those ages 4 to 7 years ( $43.1 \%$ more likely), 8 to 12 years ( $97.7 \%$ more likely), 13 years and older ( $69.8 \%$ more likely), but only slightly less likely for ages 1 to 3 years ( $0.5 \%$ less likely). Compared to Black children, White children were $16.0 \%$ and Other children were $20.4 \%$ more likely to be in the AR path.

The odds of AR path decreased by $3.2 \%$ for every one unit increase in the county housing vacancy level and decreased by $16.3 \%$ for every one unit increase in the county unemployment level. However, the odds of AR path increased by $1.7 \%$ for every one unit increase in the county child poverty level. Cases in counties with more than $25 \%$ of households on public assistance were 2.78 times more likely to be in the AR path when compared to cases in counties with less than $25 \%$ of households on public assistance. The odds of AR path decreased by $92.9 \%$ for cases in states with DR for 10 or more years when compared to cases in states with DR for less than 10 years.

In the final model, covariance parameters (see Table 9) for the county level were significant $(0.588, \mathrm{SE}=0.097, \mathrm{p}<.001,[0.426,0.811])$; and ICC indicated that approximately $12.30 \%$ of variability in the outcome variable was between counties. 
The final model fit demonstrated $74.4 \%$ overall correct prediction of the outcome variable, an improvement of $5.1 \%$ over the unconditional model. 


\section{CHAPTER 5}

\section{DISCUSSION}

The primary objective of this study was to identify the potential significance of county-level community variables in the investigative (non-AR) and non-investigative alternative response (AR) paths of the Differential Response Model of child protective services practice. Results showed that differences exist in child, family, and case characteristics between cases in AR and non-AR paths and that countylevel community factors do have significant relationships to AR and non-AR paths in the DRM. The county-level variables for housing vacancy, unemployment, child poverty, and households with public assistance were significant in predicting DRM path. Odds of AR path decreased with increased housing vacancy and unemployment, but slightly increased as child poverty increased. Odds of AR path increased with increased percentage of households receiving public assistance and for referrals in states with DRM in practice less than ten years. Results also suggested that AR path is more likely for cases from non-mandated reporters; children older than three years of age; reports with one child; cases of neglect, deprivation, or other maltreatment type; White and Other children when compared to Black children; and less likely for sexual abuse cases and referrals in states with DRM in practice more than ten years. Using the study results to answer the research questions, it is clear that there are some differences in child, family, and 
case characteristics between cases in AR and non-AR paths. It is also clear that some county-level community variables have a significant relationship to the DRM AR and non-AR paths.

\section{Limitations}

Given the large number of IVs and very large sample size, it is important to note that the study was well over powered with the potential for results that demonstrated statistical significance without having meaningful clinical significance (Cohen, 1988; Mertler \& Vannatta, 2005). Attention to theoretical considerations and the existing literature helped to distinguish trivial statistical significance from meaningful practical significance. As identified in Table 7, there was one categorical outcome variable (DV) with two levels, and multiple predictor variables (IV) measured at the categorical or continuous level.

Statistical techniques for categorical DVs and multiple mixed level IVs are limited (Mertler \& Vannatta, 2005). Univariate, bivariate, and binary logistic regression provided information about the variables in each of the levels separately. However, IBM SPSS Statistics (Version 22) for Windows was unable to process some non-parametric correlational measures because of the large number of cases in the dataset.

In recognition of the interactive theoretical model in which variables in each level may influence and be influenced by variables in other levels, study questions required examination of data nested in multiple levels. Multilevel modeling techniques for categorical DVs, such as used in this study and available in IBM SPSS Statistics (Version 22) for Windows, were necessary for the complex 
computations required to analyze categorical outcomes of data in multiple levels. It is essential to correctly specify measurement level of each variable for the advanced multilevel modeling techniques in SPSS (Version 22) in which categorical variables are called factors and continuous variables are called covariates. With the use of MLM procedures, multiple possible model solutions may be presented. The researcher assessed multiple models and obtained a final model which best fit the study data, variables considered, and the research questions; but it does not represent the only solution. The use of MLM and identification of fixed effects within the models does not imply causality.

Consideration must also be given to the modifiable areal unit problem (MAUP), which recognizes that results for indicator variables may differ depending on the choice of areal unit (Aron et al., 2010). The dataset for this study provided child level information, but identifying information such as addresses and zip codes were removed prior to release to researchers. Aggregation at the county level was possible by using Federal Information Processing Standards (FIPS) codes for those counties with more than 1,000 records. Counties with less than 1,000 records were de-identified and aggregated into a singular "other" county (U.S. DHHS, 2011c). Utilizing county as the areal level for aggregation may affect reliability and validity of the results, particularly in counties with low populations, greater heterogeneity in the population, or rarity in the occurrence of variables of interest (Aron et al., 2010, Coulton \& Korbin, 2007).

It is important to recognize that these results are limited to the study group and cannot be generalized to other groups or populations. The variable 
relationships studied relate only to reports of new cases of alleged maltreatment referred to CPS agencies in selected states. No hierarchy of maltreatment types was presumed or applied, and no inferences about co-occurrence of maltreatment type can be made. Though data for NCANDS maltreatment type variables were insufficient for examining co-occurring types of maltreatment in the present study, the issue is important and deserves further study.

No inferences can be made regarding substantiation or recurrence of maltreatment, or subsequent reports of alleged maltreatment. Multiple studies show that defining child maltreatment in terms of legal criteria and CPS investigation data is inadequate for assessing the scope and magnitude of the problem and significantly underestimates the incidence and prevalence of child maltreatment (Coohey, 2007; Cross \& Casanueva, 2009; Crume et al., 2002; Everson et al., 2008; Hussey et al., 2005; Kohl et al., 2009; Runyan et al., 2005; Sedlak et al., 2010; and Swahn et al., 2006; Theodore et al., 2005). Though the DR model of CPS practice provides the opportunity to recognize and assist children and families in need without official determination or substantiation of maltreatment and without reporting the alleged perpetrator to a central registry, it is possible that the DR model of CPS practice contributes to underestimation of child maltreatment incidence and prevalence, underreporting of suspected maltreatment, and failure to identify repeat perpetrators.

\section{Future Research}

Research on DR continues to evolve. Further research is needed to determine the impact of DR models on child maltreatment data and surveillance and 
to modify maltreatment definitions to include children who are in fact, if not in law, victims of maltreatment. Results are mixed for evidence regarding the effectiveness of DR and its relationship to variables such as child, caregiver, and case characteristics; worker satisfaction; family satisfaction and engagement; services delivered; and cost effectiveness (e.g., Conley \& Berrick, 2010, Loman \& Siegel, 2004). Whether the mixed outcomes in DR research result from assignment to a non-investigative path, services provided, attributes of the interaction between family and caseworkers, or other factors is unknown. Such mixed results regarding DR indicate the need for further research to identify and disentangle factors affecting DR at multiple levels.

The study finding that AR path is less likely for referrals in states with DRM in practice more than ten years was unexpected. It is unknown if this finding is a function of systemic, caseworker, or case characteristics. It is possible that streamlined function, more selective screening, funding, resource availability, or other factors are involved. Further research is needed to identify relationships resulting in study findings of increased odds of AR path for child poverty and for increased households receiving public assistance and decreased odds of AR path with increased housing vacancy and increased unemployment. Examination of additional economic measures, such as family and community poverty, with stratification by race and maltreatment type, may help to clarify variable relationships. In addition to housing vacancy and unemployment, there are likely other measures of social disorganization that deserve attention, such as decreased availability of resources for medical, mental health, or social support services or 
inability to access available services because of time, money, or transportation barriers.

It is important to identify the impact of these issues and measures within the context of DRM paths and to determine if modifications of county-level community factors can improve community health and have a positive impact on child maltreatment, safety, and well-being. If so, it would make sense to adjust practice to include attention to needs of the communities in which referred children and their families reside. To advance research, inform policy and practice, and produce longterm positive outcomes in child maltreatment prevention and intervention requires attention to and additional research of interactive factors and processes in multiple domains.

\section{Implications}

Personal, social, and economic consequences of child maltreatment are significant. Ongoing crises in funding and health care have contributed to evolving policy and service changes with budget cuts and service reductions. Families and their children with actual or potential maltreatment issues may have greater difficulty in accessing resources to meet needs for prevention or intervention. The DR model represents an approach that may foster collaborative relationships with families, CPS workers, and community resources including nurses and other health care professionals. The success of such a collaborative approach may depend on the availability of and access to community resources.

To help children and families in need, it is important that nurses have knowledge of and are able to successfully interact with the evolving child welfare 
system. Nurses can play a pivotal role in child maltreatment prevention and intervention efforts. Sensitivity to and understanding of community factors such as employment and poverty levels, housing conditions, and resources available can enhance nursing practice by assisting the nurse in identifying and responding to family needs within the context of the community. The nurse's role is further enhanced not only by identification of resource personnel with expertise in child welfare issues, but also by becoming experts in nursing assessment, planning and intervention for those maltreated or at risk of maltreatment. Collaboration with other resource personnel and agencies can facilitate timely and appropriate management and care for children and families with unresolved and often complex needs. Establishment of relationships and ongoing collaboration with community resources, social services, and CPS agencies are essential functions in helping to protect and support children and families. With engagement of families and community members, policies and practice can be directed at alleviating modifiable risk factors, strengthening protective factors and providing support. 
APPENDIX A

UNIVERSITY OF MISSOURI-KANSAS CITY INSTITUTIONAL

REVIEW BOARD EXEMPTION 
From: barrethr@umkc.edu [mailto:barrethr@umkc.edu]

Sent: Friday, August 31, 2012 2:37 PM

To: Cheng, An-Lin

Cc: Barreth, Rebekah; McCallum, Karen (UMKC-Student)

Subject: Study SS12-146 - NHSR: Community Factors in Differential Responses of Child Protective Services

August 31, 2012

An-Lin Cheng, Ph.D.

UMKC - School of Nursing

Kansas City, MO 64108

\section{RE: SSIRB Protocol \#: SS12-146 - NHSR - Community Factors in Differential Responses of Child Protective Services}

\section{Dear Dr. Cheng,}

Thank you for contacting the SSIRB about your proposed project. The SSIRB's subject matter jurisdiction is limited to research as defined in the Federal Policy for the Protection of Human Subjects - 45 CFR 46.102(d). "Research" is defined by these regulations as " a systematic investigation, including research development, testing and evaluation, designed to develop or contribute to generalizable knowledge." The regulations define a "Human Subject" as "a living individual about whom an investigator (whether professional or student) conducting research obtains: data through intervention or interaction with the individual, or identifiable private information."

Based upon your description of your project it does not meet the criteria to be considered human subjects research and therefore the SSIRB has no authority to review it.

Please contact the administrative office of the SSIRB (email: umkcssirb@umkc.edu; phone: 816-235-5927) if you have questions.

Thank you,

\section{SSIRB Administrative Office}

This e-mail is an official notification intended only for the use of the recipient(s). If you have received this communication in error, please return it to the sender immediately and delete any copy of it from your computer system. 
APPENDIX B

DATA LICENSE: NATIONAL CHILD ABUSE AND NEGLECT DATA SYSTEM CHILD FILE 


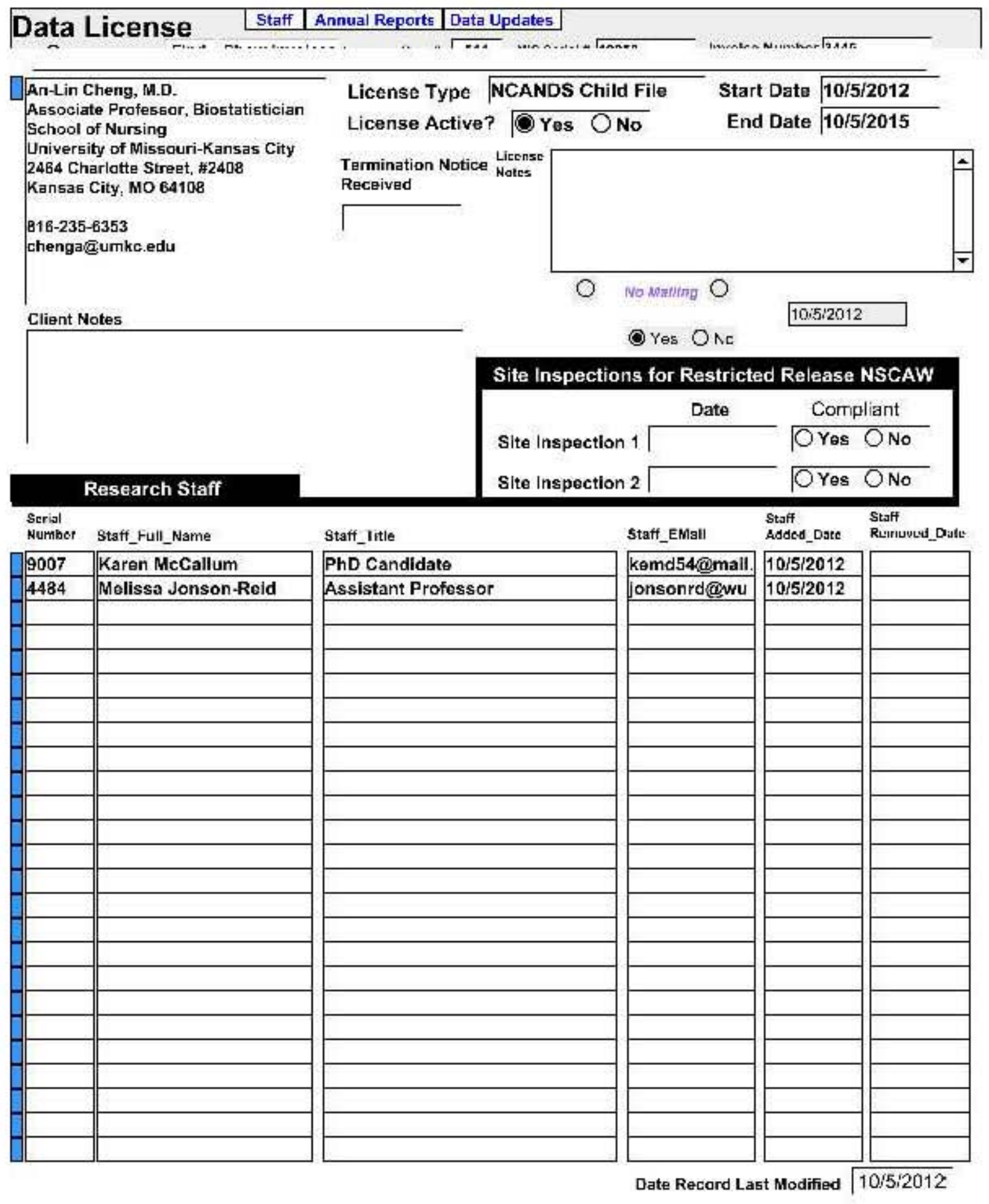




\section{REFERENCES}

Algood, C. L., Hong, J. S., Gourdine, R. M., \& Williams, A. B. (2011). Maltreatment of children with developmental disabilities: An ecological systems analysis. Children and Youth Services Review, 33, 1142-1148. doi:10.1016/j.childyouth.2011.02.003

Aron, S. B., McCrowell, J., Moon, A., Yamano, R., Roark, D. A., Simmons, M., ... Drake, B. (2010). Analyzing the relationship between poverty and child maltreatment: Investigating the relative performance of four levels of geographic aggregation. Social Work Research, 34(3), 169-179.

Ashton, V. (2004). The effect of personal characteristics on reporting child maltreatment. Child Abuse and Neglect, 28, 985-997. doi:10.1016/j.chiabu.2004.03.012

Baird, C., \& Wagner, D. (2000). The relative validity of actuarial- and consensusbased risk assessment systems. Children and Youth Services Review, 22, 839-871.

Baumann, D. J., Dalgleish, L., Fluke, J., \& Kern, H. (2011). The decision-making ecology. Washington, DC: American Humane Association.

Baumann, D. J., Law, J. R., Sheets, J., Reid, G., \& Graham, J. C. (2005). Evaluating the effectiveness of actuarial risk assessment models. Children and Youth Services Review, 27, 465-490. doi:10.1016/j.childyouth.2004.09.004

Baumann, D. J., Law, J. R., Sheets, J., Reid, G., \& Graham, J. C. (2006). Remarks concerning the importance of evaluating actuarial risk assessment models: A 
rejoinder to Will Johnson. Children and Youth Services Review, 28, 715-725. doi:10.1016/j.childyouth.2005.08.005

Belsky, J. (1980). Child maltreatment: An ecological integration. American Psychologist, 35, 320-355.

Belsky, J. (1993). Etiology of child maltreatment: A developmental-ecological analysis. Psychological Bulletin, 114, 413-434.

Black, D. A., Heyman, R. E., \& Slep, A. M. (2001). Risk factors for child physical abuse. Aggression and Violent Behavior, 6, 121-.188.

Bronfenbrenner, U. (1977). Toward an experimental ecology of human development. American Psychologist, 32, 513-531.

Camasso, M. J., \& Jagannathan, R. (2000). Modeling the reliability and predictive of risk assessment in child protective services. Children and Youth Services Review, 22, 873-896.

Campbell, K. A., Cook, L. J., LaFleur, B. J., \& Keenan, H. T. (2010). Household, family, and child risk factors after an investigation for suspected child maltreatment: A missed opportunity for prevention. Archives of Pediatric and Adolescent Medicine 164, 943-949.

CAPTA, Child Abuse Prevention, Adoption and Family Services Act of 1988, 42 U.S.C. 5101 et seq. (1988).

CAPTA, Child Abuse Prevention and Treatment Act of 1996, 42 U.S.C. 5101 et seq. (1996).

CAPTA, Child Abuse Prevention and Treatment Act of 1996, 42 U.S.C. 5101 et seq. (2010). 
Casey Family Programs. (2011a). State Child Welfare Policy Database. Retrieved from http://www.childwelfarepolicy.org

Casey Family Programs. (2011b). State Child Welfare Policy Database: Scope of DR implementation. Retrieved from http://www.childwelfarepolicy.org/maps/single?id=188

Casey Family Programs. (2011c). State Child Welfare Policy Database: Services provided through DR pathways. Retrieved from http://www.childwelfarepolicy.org/maps/multi?id=208

Center for Child and Family Policy, Terry Sanford Institute, Duke University. (2006). Multiple Response System (MRS) Evaluation Report to the North Carolina Division of Social Services (NCDSS). Retrieved from http://www.ncdhhs.gov/dss/publications/docs/mrs eval rpt 63006 all com bined.pdf

Child Welfare Information Gateway. (2008). Differential response to reports of child abuse and neglect. Retrieved from http://www.childwelfare.gov/pubs/issue briefs/differential response

Child Welfare Information Gateway. (2009). Making and screening reports of child abuse and neglect. Retrieved from http://www.childwelfare.gov/systemwide/laws policies/statutes/repproc.cfm Child Welfare Information Gateway. (2012). Mandatory reporters of child abuse and neglect. Retrieved from http://www.childwelfare.gov/systemwide/laws policies/statutes/manda.cfm 
Child Welfare Information Gateway. (2013). Preventing child maltreatment and promoting well-being: A network for action 2013 resource guide. Retrieved from http://www.childwelfare.gov/preventing

Cohen, J. (1988). Statistical power analysis for the behavioral sciences. (2nd ed.). New York, NY: Psychology Press, Taylor \& Francis Group.

Conley, A. (2007). Differential response: A critical examination of a secondary prevention model. Children and Youth Services Review, 29, 1454-1468. doi:10.1016/j.childyouth.2007.06.003

Conley, A., \& Berrick, J. D. (2010). Community-based child abuse prevention: Outcomes associated with a differential response program in California. Child Maltreatment, 15, 282-292. doi:10.1177/1077559510376236

Connell, C. M., Bergeron, N., Katz, K. H., Saunders, L., \& Tebes, J. K. (2007). Rereferral to child protective services: The influence of child, family, and case characteristics on risk status. Child Abuse and Neglect, 31, 573-588. doi:10.1016/j.chiabu.2006.12.004

Coohey, C. (2006). How Child Protective Services investigators decide to substantiate mothers for failure-to-protect in sexual abuse cases. Journal of Child Sexual Abuse, 15(4), 61-81. doi:10.1300/J070v15n04_04

Coohey, C. (2007). What criteria do Child Protective Services investigators use to substantiate exposure to domestic violence? Child Welfare, 86(4), 93-122.

Coulton, C. J., Korbin, J., Chan, T., \& Su, M. (2001). Mapping residents' perceptions of neighborhood boundaries: A methodological note. American Journal of Community Psychology, 29, 371-382. 
Coulton, C. J., \& Korbin, J.E. (2007). Indicators of child well-being through a neighborhood lens. Social Indicators Research, 84, 349-361. doi:10.1007/s11205-007-9119-1

Coulton, C. J., Korbin, J. E., Su, M., \& Chow, J. (1995). Community level factors and child maltreatment rates. Child Development, 66, 1262-1276.

Cross, T. P., \& Casanueva, C. (2009). Caseworker judgments and substantiation. Child Maltreatment, 14, 38-52. doi:10.1177/1077559508318400

Crume, T. L., DiGuiseppi, C., Byers, T., Sirotnak, A. P., \& Garrett, C. J. (2002). Underascertainment of child maltreatment fatalities by death certificates, 1990-1998. Pediatrics, 110(2 Pt 1), e18. doi:10.1542/peds.110.2.e18

D’Andrade, A., Benton, A., Austin, M. J. (2005, July). Risk and safety assessment in child welfare: Instrument comparisons. Retrieved from Center for Social Services Research, School of Social Welfare, University of California at Berkeley website http://cssr.berkeley.edu/research units/bassc/project details.html

DePanfilis, D., \& Girvin, H. (2005). Investigating child maltreatment in out-of-home care: Barriers to effective decision-making. Children and Youth Services Review, 27, 817-851. doi:10.1016/j.childyouth.2004.11.010

Drake, B. (2013). Differential response: What to make of the existing research? A response to Hughes et al. Research on Social Work Practice, 35, 539-544.. doi:10.1177/1049731512474492

Drake, B. (1996). Unraveling "unsubstantiated". Child Maltreatment, 1, 261-271. doi:10.1177/1077559596001003008 
Drake, B., Jonson-Reid, M., Way, I., \& Chung, S. (2003). Substantiation and recidivism. Child Maltreatment, 8, 248-260. doi:10.1177/1077559503258930

Drake, B., \& Jonson-Reid, M. (2000). Substantiation and early decision points in public child welfare: A conceptual reconsideration. Child Maltreatment, 5, 227-235. doi:10.1177/1077559500005003003

English, D. J., Marshall, D. B., Coghlan, L., Brummel, S., \& Orme, M. (2002). Causes and consequences of the substantiation decision in Washington State Child Protective Services. Children and Youth Services Review, 24, 817-851.

English, D. J., Upadhyaya, M. P., Litrownik, A. J., Marshall, J. M., Runyan, D. K., Graham, J. C., \& Dubowitz, H. (2005). Maltreatment's wake: The relationship of maltreatment dimensions to child outcomes. Child Abuse and Neglect, 29, 597-619. doi:10.1016/j.chiabu.2004.12.008

English, D. J., Wingard, T., Marshall, D, Orme, M., \& Orme, A. (2000). Alternative responses to child protective services: Emerging issues and concerns. Child Abuse and Neglect, 24, 375-388.

Ernst, J. S. (2000). Mapping child maltreatment: Looking at neighborhoods in a suburban county. Child Welfare, 79, 555-572.

Ernst, J. S. (2001). Community-level factors and child maltreatment in a suburban county. Social Work Research, 25(3), 133-142.

Everson, M. D., Smith, J. B., Hussey, J. M., English, D., Litrownik, A. J., Dubowitz, H., . . Runyan, D. K. (2008). Concordance between adolescent reports of childhood abuse and Child Protective Service determinations in an at-risk 
sample of young adolescents. Child Maltreatment, 13, 14-26.

doi:10.1177/1077559507307837

Fakunmoju, S. B. (2009). Substantiation and adverse appeal outcomes: Content analysis and testing of Drake's harm/evidence model. Child Maltreatment, 14, 53-68. doi:10.1177/1077559508320386

Fang, X., Brown, D. S., Florence, C. S., \& Mercy, J. A. (2012). The economic burden of child maltreatment in the United States and implications for prevention. Child Abuse and Neglect, 36, 156-165. doi:10.1016/j.chiabu.2011.10.006

Fink, A. (2010). Conducting research literature reviews: From the Internet to paper (3rd ed.). Los Angeles, CA: Sage.

Finkelhor, D., Ormrod, R., Turner, H., \& Hamby, S. L. (2005). The victimization of children and youth: A comprehensive, national survey. Child Maltreatment, 10, 5-25. doi:10.1177/1077559504271287

Franke, T., Bagdasaryan, S., \& Furman, W. (2011). Differential response in rural counties: Path differentiation, service receipt, and case disposition. Journal of Public Child Welfare, 1, 1-22. doi:10.1080/15548732.2010.526900

Freisthler, B. (2004). A spatial analysis of social disorganization, alcohol access, and rates of child maltreatment in neighborhoods. Children \& Youth Services Review, 26, 803-819. doi:10.1016/j.childyouth.2004.02.022

Freisthler, B., Gruenewald, P. J., Remer, L. G., Lery, B., \& Needell, B. (2007). Exploring the spatial dynamics of alcohol outlets and child protective services referrals, substantiations, and foster care entries. Child Maltreatment, 17(2), 114-124. doi:10.1177/1077559507300107 
Freisthler, B., Midanik, L. T., \& Gruenewald, P. J. (2004). Alcohol outlets and child physical abuse and neglect: Applying Routine Activities Theory to the study of child maltreatment. Journal of Studies on Alcohol, 65, 586-592.

FRIENDS National Resource Center for Community-Based Child Abuse Prevention (2007). Alternative response systems: Learning tool 13. Chapel Hill, NC: FRIENDS National Resource Center for Community-Based Child Abuse Prevention. Retrieved from http://www.friendsnrc.org/joomdocs/ars.pdf

Gilbert, R., Widom, C. S., Browne, K., Fergusson, D., Webb, E., \& Janson, S. (2009). Burden and consequences of child maltreatment in the high-income countries. Lancet, 373, 68-81. doi:10.1016/S0140-6736(08)61706-7

Graham, S., Weiner, B., Cobb, M., \& Henderson, T. (2001). An attributional analysis of child abuse among low-income African-American mothers. Journal of Social and Clinical Psychology, 20, 233-257.

Hamilton, L. R. (1989). Variables associated with child maltreatment and implications for prevention and treatment. Early Child Development and Care, 42, 31-56.

Hammond, W. R., Haegerich, T. M., \& Saul, J. (2009). The public health approach to youth violence and child maltreatment prevention at the Centers for Disease Control and Prevention. Psychological Services, 6, 253-263. doi:10.1037/a0016986

Heck, R. H., Thomas, S. L., \& Tabata, L. N. (2010). Multilevel and longitudinal modeling with IBM SPSS. New York, NY: Routledge. 
Herring, D. J. (2009). Fathers and child maltreatment: A research agenda based on evolutionary theory and behavioral biology research. Children and Youth Services Review, 31, 935-945. doi:10.1016/j.childyouth.2009.04.007

Hussey, J. M., Chang, J. J., \& Kotch, J. B. (2006). Child maltreatment in the United States: Prevalence, risk factors, and adolescent health consequences. Pediatrics, 118, 933-942. doi:10.1542/peds.2005-2452

Hussey, J. M., Marshall, J. M., English, D. J., Knight, E. D., Lau, A. S., Dubowitz, H., \& Kotch, J. B. (2005). Defining maltreatment according to substantiation: Distinction without a difference? Child Abuse and Neglect, 29, 479-492. doi:10.1016/j.chiabu.2003.12.005

Johnson, W. (2006). The risk assessment wars: A commentary response to "Evaluating the effectiveness of actuarial risk assessment models" by Donald Baumann, J. Randolph Law, Janess Sheets, Grant Reid, and J. Christopher Graham, Children and Youth Services Review, 27, pp. 465-490. Children and Youth Services Review, 28, 704-714. doi:10.1016/j.childyouth.2005.07.007 Jonson-Reid, M., Drake, B., \& Kohl, P. L. (2009). Is the overrepresentation of the poor in child welfare caseloads due to bias or need? Children and Youth Services Review, 31, 422-427. doi:10.1016/j.childyouth.2008.09.009 Jonson-Reid, M., Drake, B., \& Zhou, P. (2013). Neglect subtypes, race, and poverty: Individual, family, and service. Child Maltreatment, 18, 30-41. doi:10.1177/1077559512462452

Kaplan, C., \& Merkel-Holguin, L. (2008). Another look at the National Study on Differential Response in Child Welfare. Protecting Children, 23(1-2), 5-21. 
King, G., Trocme, N., \& Thatte, N. (2003). Substantiation as a multitier process: The results of a NIS-3 analysis. Child Maltreatment, 8, 173-182.

doi:10.1177/1077559503254143

Klein, S. (2011). The availability of neighborhood early care and education resources and the maltreatment of young children. Child Maltreatment, 16, 300-311. doi:10.1177/10775595511428801

Kohl, P. L., Jonson-Reid, M., \& Drake, B. (2009). Time to leave substantiation behind: Findings from a national probability study. Child Maltreatment, 14, 1726. doi:10.1177/1077559508326030

Lawrence, C. N., Rosanbalm, K. D., \& Dodge, K. A. (2011). Multiple response system: Evaluation of policy change in North Carolina's child welfare system. Children and Youth Services Review, 33, 2355-2365.

doi:10.1016/j.childyouth.2011.08.007

Lee, S. J., Guterman, N., \& Lee, Y. (2008). Risk factors for paternal physical child abuse. Child Abuse and Neglect, 32, 846-858. doi:10.1016/j.chiabu.2007.11.006

Leeb, R. T., Paulozzi, L. J., Melanson, C., Simon, T. R., \& Arias, I. (2008) Child maltreatment surveillance: Uniform definitions for public health and recommended data elements, version 1.0. Atlanta (GA): Centers for Disease Control and Prevention, National Center for Injury Prevention and Control.

Little, L., \& Kantor, G. K. (2002). Using ecological theory to understand intimate partner violence and child maltreatment. Journal of Community Health Nursing, 19, 133-145. doi:10.1207/S15327655JCHN1903_02 
Loman, L. A. (2005). Differential response improves traditional investigations: Criminal arrests for severe physical and sexual abuse. St. Louis, MO: Institute of Applied Research. Retrieved from http://www.iarstl.org/papers/MODiffResp2004a.pdf

Loman, L. A., \& Siegel, G. L. (2004). Differential response in Missouri after five years: Final report. St. Louis, MO: Institute of Applied Research. Retrieved from http://www.iarstl.org/assets/pdf/children/differential-response/pc-dr$\underline{\text { severe-abuse-mopdf.pdf }}$

Madsen, M. D., \& Abell, N. (2010). Trauma Resilience Scale: Validation of protective factors associated with adaptation following violence. Research on Social Work Practice, 20, 223-233. doi:10.1177/1049731509347853

McDonell, J., \& Skosireva, A. (2009). Neighborhood characteristics, child maltreatment, and child injuries. Child Indicators Research, 2, 133-153. doi:10.1007/s12187-009-9038-6

Merkel-Holguin, L., Kaplan, C., \& Kwak, A. (2006). National Study on Differential Response in Child Welfare. Washington, DC: American Humane Association and Child Welfare League of America. Retrieved from http://www.americanhumane.org/assets/pdf/children/pc-2006-national-studydifferential-response.pdf

Mertler, C. A., \& Vannatta, R. A. (2005). Advanced and multivariate statistical methods (3rd ed.). Glendale, CA: Pyrczak Publishing.

National Quality Improvement Center on Differential Response in Child Protective Services. (2009). Online survey of state differential response policies and 
practices findings report. Washington, DC: NQIC. Retrieved from http://www.differentialresponseqic.org/assets/docs/qic-dr-findings reportjun09.pdf

National Research Council. (1993). Understanding child abuse and neglect. Washington, DC: National Academies Press. Retrieved from http://www.nap.edu/catalog/2117.html

National Survey of Child and Adolescent Well-Being (NSCAW) Research Group (2002). Methodological lessons from the National Survey of Child and Adolescent Well-being: The first three years of the USA's national probability study of children and families investigated for abuse and neglect. Children and Youth Services Review, 24, 513-541.

Ortiz, J. J., Shusterman, G. R., \& Fluke, J. D. (2008). Outcomes for children with allegations of neglect who receive alternative response and traditional investigations: Findings from NCANDS. Protecting Children, 23(1-2), 57-70.

Palusci, V. J. (2011). Risk factors and services for child maltreatment among infants and young children. Children and Youth Services Review, 33, 1374-1382. doi:10.1016/j.childyouth.2011.04.018

Paulsen, D. J. (2003). No safe place: Assessing spatial patterns of child maltreatment victimization. Journal of Aggression, Maltreatment \& Trauma, 8(1/2), 63-85. doi:10.1300/JI46v08n01_03

Richardson, J. (2008). Differential response: Literature review. Urbana, IL: Children and Family Research Center, University of Illinois School of Social Work. Retrieved from http://www.state.il.us/DCFS/docs/DRLitreview 11.21.09.pdf 
Runyan, D. K., Cox, C. E., Dubowitz, H., Newton, R. R., Upadhyaya, M., Kotch, J. B., . . Knight, E. D. (2005). Describing maltreatment: Do child protective service reports and research definitions agree? Child Abuse and Neglect, 29, 461-477. doi:10.1016/j.chiabu.2004.06.015

Ryan, S., Wiles, D., Cash, S., \& Siebert, C. (2005). Risk assessments: Empirically supported or values driven? Children and Youth Services Review, 27, 213225. doi:10.1016/j.childyouth.2004.09.003

Sawyer, R., \& Lohrbach, S. (2005a). Differential response in child protection: Selecting a pathway. Protecting Children, 20(2-3), 44-53.

Sawyer, R., \& Lohrbach, S. (2005b). Integrating domestic violence intervention into child welfare practice. Protecting Children, 20(2-3), 62-77.

Schene, P. (2001). Meeting each family's needs: Using differential response in reports of child abuse and neglect. Best Practice/Next Practice, 2(1), 1-6.

Schene, P. (2005). The emergence of differential response. Protecting children, 20(2-3), 4-7.

Schumacher, J. A., Slep, A. M., \& Heyman, R. E. (2001). Risk factors for child neglect. Aggression and Violent Behavior, 6, 231-254.

Sedlak, A. J., Mettenburg, J., Basena, M., Petta, I. McPherson, K., Greene, A., \& Li, S. (2010). Fourth National Incidence Study of Child Abuse ad Neglect (NIS4): Report to Congress. Washington, DC: U.S. Department of Health and Human Services, Administration for Children and Families.

Shusterman, G. R., Hollinshead, D. Fluke, J. D., \& Yuan, Y.T. (2005). Alternative responses to child maltreatment: Findings from NCANDS. Washington, DC: 
U.S. Department of Health and Human Services, Office of the Assistant Secretary for Planning and Evaluation. Retrieved from http://aspe.hhs.gov/hsp/05/child-maltreat-resp/report.pdf

Siegel, G. L., \& Loman, L. A. (2006). Extended follow-up study of Minnesota's Family Assessment Response: Final report. St. Louis, MO: Institute of Applied Research. Retrieved from http://www.iarstl.org/papers/FinalMNFARReport.pdf

Slack, K. S., Berger, L. M., DuMont, K., Yang, M., Kim, B., Ehrhard-Dietzel, S., \& Holl, J. L. (2011). Risk and protective factors for child neglect during early childhood: A cross-study comparison Children and Youth Services Review, 33, 1354-1363. doi:10.1016/j.childyouth.2011.04.024

Smith, C. A., Ireland, T. O., Thornberry, T. P., \& Elwyn, L. (2008). Childhood maltreatment and antisocial behavior: Comparison of self-reported and substantiated maltreatment. American Journal of Orthopsychiatry, 78, 173186. doi:10.1037/0002-9432.78.2.173

Stith, S. M., Liu, L., Davies, C., Boykin, E. L., Alder, M. C., Harris, J. M., ... Dees, J. E. (2009). Risk factors in child maltreatment: A meta-analytic review of the literature. Aggression and Violent Behavior, 14, 13-29.

doi:10.1016/j.avb.2006.03.006

Swahn, M. H., Whitaker, D. J., Pippen, C. B., Leeb, R. T., Teplin, L. A., Abram, K. M., \& McClelland, G. M. (2006). Concordance between self-reported maltreatment and court records of abuse or neglect among high-risk youths. American Journal of Public Health, 96, 1849-1853. 
Theodore, A. D., Chang, J. J., Runyan, D. K., Hunter, W. M., Bangdiwala, S. I., \& Agans, R. (2005). Epidemiologic features of the physical and sexual maltreatment of children in the Carolilnas. Pediatrics, 115(3), e331-e337. doi:10.1542/peds.2004-1033

Theodore, A., Runyan, D., \& Chang, J. J. (2007). Measuring the risk of physical neglect in a population-based sample. Child Maltreatment, 12, 96-105. doi:10.1177/1077559506296904

U.S. Census Bureau. (2008). A compass for understanding and using American Community Survey Data: What general data users need to know. Washington, DC: U.S. Government Printing Office.

U.S. Census Bureau. (2011). The 2008-2010 ACS 3-year summary file technical documentation (Version 1). Washington, DC: U.S. Government Printing Office.

U.S. Department of Health and Human Services, Administration for Children and Families (2005). National Survey of Child and Adolescent Well-being: CPS sample component, Wave I data analysis report. Washington, DC: U.S. Government Printing Office.

U.S. Department of Health and Human Services, Administration for Children and Families, Administration on Children, Youth and Families, Children's Bureau. (2011a). Child Maltreatment 2010. Washington, DC: U.S. Government Printing Office.

U.S. Department of Health and Human Services, Administration for Children and Families, Administration on Children, Youth and Families, Children's Bureau. 
(2011b). National Child Abuse and Neglect Data System (NCANDS) Agency

File, FFY 2010 (Dataset 166). Ithaca, NY: National Data Archive on Child

Abuse and Neglect, Family Life Development Center, Cornell University.

Available from http://www.ndacan.cornell.edu

U.S. Department of Health and Human Services, Administration for Children and

Families, Administration on Children, Youth and Families, Children's Bureau.

(2011c). National Child Abuse and Neglect Data System (NCANDS) Child

File, FFY 2010 (Dataset 165). Ithaca, NY: National Data Archive on Child

Abuse and Neglect, Family Life Development Center, Cornell University.

Available from http://www.ndacan.cornell.edu

U.S. Department of Health and Human Services, Administration for Children and Families, Children's Bureau, and Office of the Assistant Secretary for Planning and Evaluation (2003). National Study of Child Protective Services Systems and Reform Efforts: Findings on local CPS practices. Washington, DC: U.S. DHHS. Retrieved from http://aspe.hhs.gov/hsp/cps-status03/cpspractices03

Waldfogel, J. (1998). Rethinking the paradigm for child protection. The Future of Children, 8(1), 104-119.

Wang, C., \& Holton, J. (2007). Total estimated cost of child abuse and neglect in the United States. Chicago, IL: Prevent Child Abuse America.

Weissman, A. M., Jogerst, G. J., \& Dawson, J.D. (2003). Community characteristics associated with child abuse in lowa? Child Abuse and Neglect, 27, 11461159. doi:10.1016/j.chiabu.2003.09.002 
Whitaker, D. J., Lutzker, J. R., \& Shelley, G. A. (2005). Child maltreatment prevention priorities at the Centers for Disease Control and Prevention. Child Maltreatment, 10, 245-259. doi:10.1177/1077559505274674

Yuan, Y. T. (2005). Potential policy implications of alternative response. Protecting Children, 20(2-3), 22-31.

Zielewski, E. H., \& Macomber, J. E. (2007). Rural families' connections to services in an alternative response system. Journal of Public Child Welfare, 1(4), 21-41. doi:10.1080/155487308021181215

Zielewski, E. H., Macomber, J., Bess, R., \& Murray, J. (2006). Families' connections to services in an alternative response systems. Washington, DC: The Urban Institute. Retrieved from http://www.urban.org/publications/311397.html 
Karen McCallum was born and raised in South Texas. After completing her initial Registered Nursing degree, she worked in a pediatric hospital where she became Clinical Supervisor for the Outpatient Department, including general and specialty clinics and the emergency department. While working full-time, she earned the Bachelor of Science in Nursing degree. This included the independent design, implementation, analyses, and reporting for a quantitative research study entitled, "Job Satisfaction Factors for Nurses in a Pediatric Hospital". She prepared reports of the findings and presented these orally and in writing to national organizations including the National League for Nursing.

Ms. McCallum then earned the Master of Science in Nursing degree with Pediatric Nurse Practitioner Certificate while continuing to work in the pediatric hospital. This included the completion of an exploratory field study entitled "School Teachers' Perceptions of Health Problems in School-Age Children from Low Income Families". She developed the semi-structured interview tool, obtained institutional review board approval and other authorizations, recruited participants, collected data, and performed data analyses. Dissemination activities included a poster presentation and oral and written presentations of findings to community and professional audiences. Additional research activities included a prospective longitudinal study entitled, "Compliance with Appointments for Pediatric Ambulatory Care". She completed this study in the dual role of student in the M.S.N. program and Clinical Supervisor of the Outpatient Department in the pediatric hospital with 
support of academic advisers and collaboration with hospital officials. She was responsible for all phases of this study. Other research activities included preparation and presentation of multiple case studies.

Within a few years of completing the M.S.N. degree, Ms. McCallum married and relocated. She worked in home health care, quality assurance, utilization review, and education while raising one son. The family relocated to Central Texas and continue to live there. Their son graduated from the University of Texas in Austin, and became gainfully employed. Ms. McCallum then began pursuit of the Ph.D. in Nursing degree at the University of Missouri-Kansas City.

Ms. McCallum is a charter member of Eta Omicron chapter of Sigma Theta Tau International. She is a past member of the National Commission of Licensure Examination-Registered Nursing Panel of Content Experts and has presented written and oral testimony to the National Commission on Nursing. She developed multiple classes and inservice seminars from concept to classroom presentation. She has participated in multiple professional seminars, meetings, and conventions. 